Weaam Sobhy Mohamed Afifi

\title{
The Effect of Cultural Distance on Translating Cultural References in al-Zayyat's The Open Door (1960)
}

\author{
By \\ Weaam Sobhy Mohamed Afifi \\ Teaching Assistant \\ Department of English Language and Literature \\ Faculty of Al-Alsun (Languages) \\ Ain Shams University, Egypt \\ Abstract
}

The cultural distance is the distance between two given cultures that is created by the fact that each culture has distinguishing characteristics that have been formed by various factors. These factors include traditions, values, religion, geography, and historical and socio-cultural developments, among others. Such aspects differ from one culture to another by varying degrees, and the differences in such aspects create the distance between two given cultures. This distance is referred to in this study as the cultural distance or the cultural gap. This study aims at investigating how far the cultural distance between Arabic and English influences the translation of cultural references, in terms of conveying their intended meaning in the source text, as well as the connotation(s) and status they have in their culture of origin to the target audience. Cultural references represent a challenging area in translation. However, they are not problematic in themselves, but in relation to the two cultures under translation. They create translation problems because they exist in one culture but not the other, or exist in the other with different value, status, connotations, etc. The wider the gap between the two cultures under translation, the more challenging it is to deal with cultural references. An evident example is the translation from Arabic into English. The complex translation problems cultural references create and the scarcity of studies on their translation from Arabic into English form the rationale of the present study. Therefore, the study conducts a descriptive qualitative analysis of the translation of cultural references in al-Zayyat's novel The Open Door (1960) and its English translation (2000), adopting Ranzato (2013) as a model of analysis. Based on the analysed data, the study demonstrates the great impact exerted by the distance between the source culture and the target culture on translating cultural references. It shows that different forms of translation loss and certain choices of translation strategy in the analysed target text are attributed to this gap.

Keywords: Culture-related translation studies, Cultural References, literary translation, cultural distance, translation strategies, translation loss 
The Effect of Cultural Distance on Translating Cultural References in al-Zayyat's The

\title{
Open Door (1960)
}

\section{تأثثير الفجوة الثقافية على ترجمة الإحالات الثقافية في روايةة الباب المفتوح} (1960) للطيفة الزيات الزئة

\author{
ملخص الخصات
}

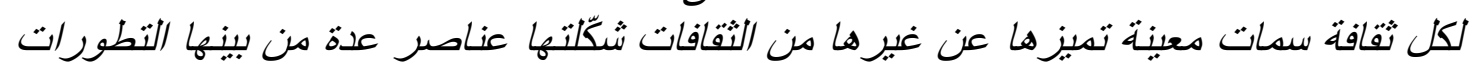

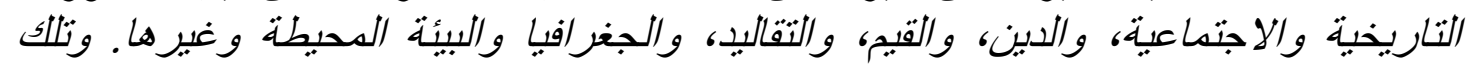

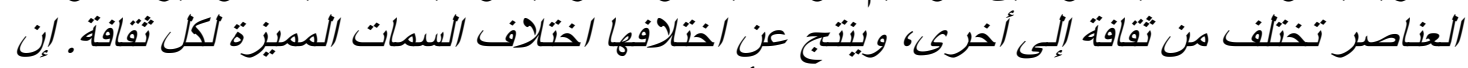

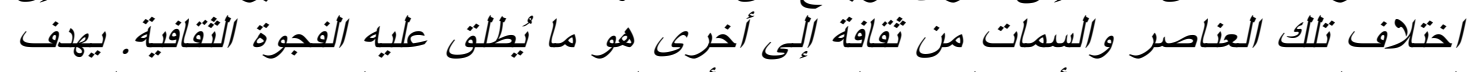

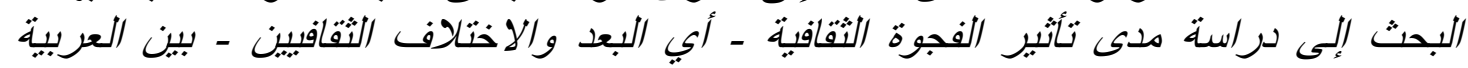

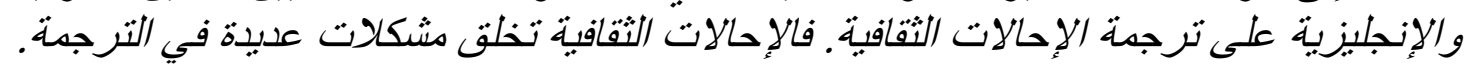

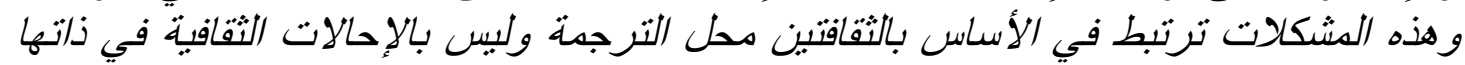

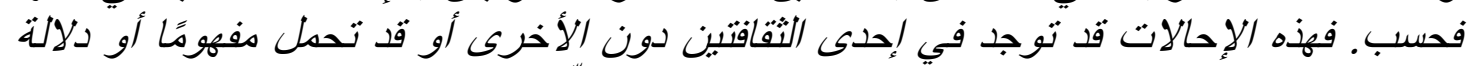

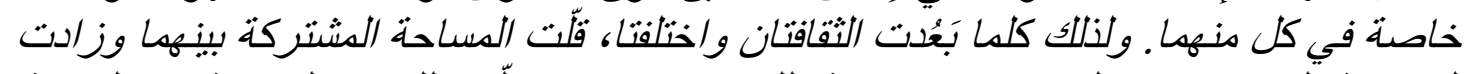

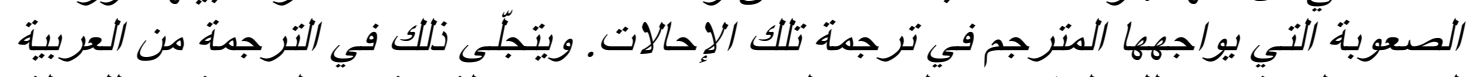

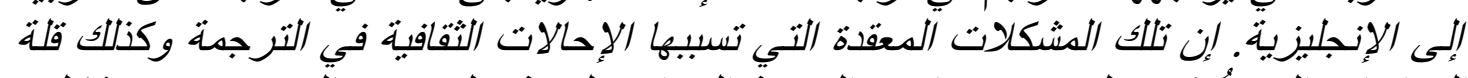

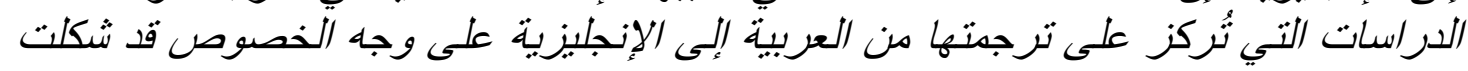

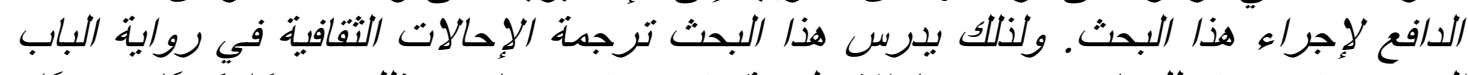

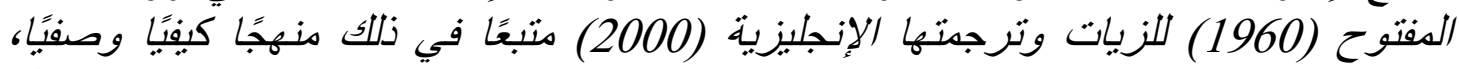

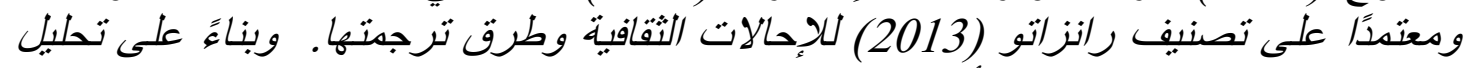

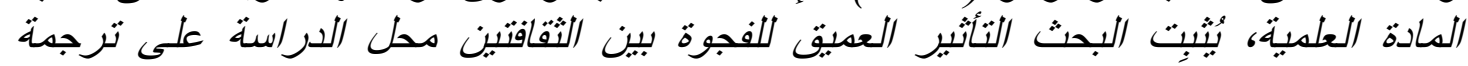

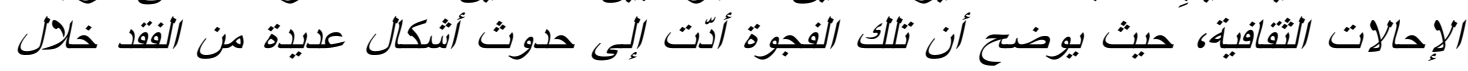

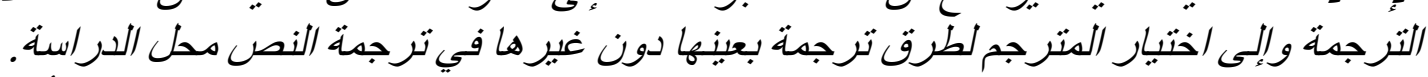

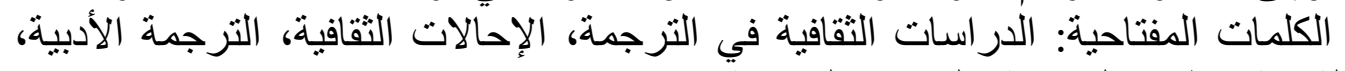

الفجوة التقافية، طرق الترجمة، الفقد في الترجمة الفية 
Weaam Sobhy Mohamed Afifi

\title{
The Effect of Cultural Distance on Translating Cultural References in al-Zayyat's The Open Door (1960)
}

\author{
By \\ Weaam Sobhy Mohamed Afifi \\ Teaching Assistant \\ Department of English Language and Literature \\ Faculty of Al-Alsun (Languages) \\ Ain Shams University, Egypt
}

Culture is a multifaceted concept that bears a highly complex interrelation with language and translation. Cultural References (CRs) reflect the various aspects of a given culture in its language. They are words and expressions that refer to objects and concepts that are more specific to one culture than another. They may carry certain connotations and associations, or have a particular status in one culture but not the other. Such references can be intralinguistic, e.g. proverbs, idioms, etc. or extralinguistic, e.g. places, food items, public figures, traditions, etc. Their cultural specificity can present a challenge in translation. This is because translation is not only a linguistic transfer between languages, but also a communication between cultures.

A more difficult challenge is to translate CRs between two languages that are somewhat far from each other in terms of culture, e.g. Arabic and English. Dickins, Hervey, and Higgins (2002) stress the existence of a cultural distance between Arabic and English as well as the translation challenges it may create in relation to conveying connotative meanings. They state that "[g]iven the relative cultural distance between the Arab world and the English-speaking world, associative meanings are likely to be a problem" in translation (p. 69). The cultural distance or gap refers to the differences in concepts, values, customs, traditions, behaviours, ways of expression, etc. between one culture and another. These differences mainly result from the distinct historical, social, geographical and religious background of each culture. This cultural distance or gap may cause a CR to have a distinct connotation or value, or be viewed from a different perspective in each of those cultures.

CRs are deeply inherent in the culture they belong to. Hence, in translation, attention should be given to the context of culture within which CRs exist. This is because audiences belonging to any given culture comprehend the reality around them through a mind map or model, which consists of their values, ideals, beliefs, etc. In other words, they make sense of any Target Text (TT) in their own context of culture, which might be different from that in which the Source Text (ST) is 
The Effect of Cultural Distance on Translating Cultural References in al-Zayyat's The Open Door (1960)

originally produced. This difference further highlights the idea of the gap existing between cultures that is discussed above.

Within this context of culture, no matter how technical or universal words seem, they can have cultural associations and connotations. For instance, "United States" is associated with "patriotism and government" for Americans, while for Mexicans it is related to "exploitation and wealth" (Díaz-Guerrero \& Szalay as cited in Katan, 2009, p. 85). Such associations are interpreted within the context of culture as they stem from people's orientations. Consequently, and in the light of the skopos theory, the translator must take into account that the TT will be interpreted from the perspective of a different mind map, a different model of reality. The way this model works may distort reality as depicted in the ST, resulting in a possible misinterpretation or stereotyping of the other (Katan, 2009, 2014).

The rationale of the present study is derived from such complicated challenges posed by CRs in translation. It also stems from the minor attention given in the translation studies literature to examining these challenges in the translation from Arabic into English specifically. Hence, the present study explores the translation of CRs between two relatively distant languages and cultures, namely from Arabic into English. Its main objective is to investigate the effect of the cultural distance between Arabic and English on how such references are translated, taking alZayyat's The Open Door (1960) as its case study. For this purpose, the study conducts a descriptive qualitative analysis of selected CR examples from the abovementioned novel and its English translation. In conducting this analysis, the study adopts the classification of CRs and their translation strategies proposed by Ranzato (2013). The following paragraphs present a background on CRs and an account of the model employed in the analysis.

Several definitions of CRs draw attention to their problematic nature in translation. For instance, Vlahov and Florin (1969, as cited in Ranzato, 2013, p. 67) describe CRs as:

words (and composed locutions) of popular language which constitute denominations of objects, concepts, which are typical of a geographical environment, of a culture, of the material life or of historical-social peculiarities of a people, a nation, a country, a tribe, and which thus carry a national, local or historical colouring; these words have not precise equivalents in other languages.

This is a clear and simple account of the features of CRs, describing them as terms that refer to objects and concepts that are 
specific to one culture but do not have equivalents in another. For Newmark (1988), CRs are those specific to one culture rather than another; they have certain cultural connotations and cause problems in translation "unless there is cultural overlap between the source and the target language (and its readership)" (p. 94). Newmark's and Vlahov and Florin's definitions are quite similar. However, Newmark's shows more clearly that translation problems depend on the distance between the two cultures and languages under translation.

Aixelá (1996) also discusses the problems created by the cultural aspect of a text in translation. He agrees with Newmark that CRs are translation problems whose nature pertains to "an intercultural gap" between the Source Culture (SC) and the Target Culture (TC) (1996, p. 57). Furthermore, in defining CRs, Aixelá emphasizes that they do not pose a problem in translation only because they exist in one culture and lack equivalents in another. They also create problems related to their status in the two cultures. This is because although there might be an overlap between cultures, CRs may still have distinct and even contrasting connotations and values in these overlapping cultures. This makes conveying CRs from one cultural group to another through translation quite challenging. To address these complex challenges, many scholars have devised typologies of CRs and their translation strategies. Following is a review of some of these typologies.

Most of the classifications of CRs are mainly based on a lexical division, i.e. types of CRs are presented as lists of lexical sets. For instance, Newmark (1988) suggests a categorization of CRs that comprises: ecology; material culture; social culture; social, political and administrative organization; and gestures and habits. Another typology of CRs is presented by Aixelá (1996). However, it is noticeably more concise compared to Newmark's, being divided into two types only: proper nouns and common expressions. For Aixelá, all CRs that are not proper nouns come under the category of common expressions with no further distinction. This poses questions regarding the applicability and practicality of this typology for text analysis.

Cintas and Remael (2007) ${ }^{1}$ classify CRs into three major categories: geographical references, ethnographical references and sociopolitical references; each has its own subcategories. They point out that another type of CRs, namely historically-bound references, can be encompassed within any of these three categories (Cintas \& Remael, 2014 , p. 201). However, although these categories and many of their subcategories are similar to those of Newmark (1988), the ethnographical references to decent, for instance, as well as the idea of CRs being historically bound have not been highlighted by Newmark nor Aixelá 
The Effect of Cultural Distance on Translating Cultural References in al-Zayyat's The Open Door (1960)

(1996). Guerra (2012) presents types of CRs that are not really distinct from the abovementioned typologies, except for a type including references to mythology, which has not been stressed that directly by those typologies. However, an aspect that Guerra's classification shares with the others is dividing CRs into lexical groups, which can hardly be comprehensive.

Instead of such lexical division, Pedersen (2005) categorizes CRs based on the concepts of transculturality (i.e. how familiar the Source Audience (SA) and the Target Audience (TA) are with a CR), and extratextuality (i.e. whether a CR is specially created for a certain text or already exists in a culture outside the text). This division allows more CRs to be included no matter what their lexical set is and considers the distance between the SC and the TC. However, it makes deciding the TA's degree of familiarity with the CR somewhat subjective, as it does not make obvious whether this degree is based on the translator's or the TA's knowledge of the CR. Being related to the distance between cultures, a CR's degree of familiarity can have a great effect on the translator's choice of strategy. The following paragraphs discuss some classifications of strategies presented in the literature on translating CRs.

Various taxonomies of translation strategies have been proposed, attempting to face the challenges CRs create in translation. Most of them present strategies in the form of a scale that goes from the most SLoriented to the most TL-oriented strategies. For example, in translating CRs, Newmark (1988) points out that the two most general translation strategies lying at the ends of a cline are those of transference and componential analysis. Aixelá (1996) also organizes his strategies on a scale that has conservation and substitution as its two ends. Each of these major categories includes some subcategories whose classification depends on the effect they exert in translation; if they tend to maintain the CR in any way, they belong to conservation, and if they tend to replace it in any way, they belong to substitution. Conservation includes the subcategories of repetition, orthographic adaptation, linguistic (noncultural) translation, extratextual gloss and intratextual gloss; and substitution includes synonymy, limited universalization, absolute universalization, naturalization, deletion and autonomous creation.

Similarly, the strategies of Dickins et al. (2002) have two extreme ends, namely, exoticism and calque, and cultural transplantation. The strategies in between are cultural borrowing and communicative translation. Pedersen's SL-oriented strategies include retention, specification and direct translation, while his TL-oriented ones are 
generalization, substitution and omission. He has one more strategy that he places outside the scale, i.e. official translation (2005, p. 4). Cintas and Remael do not follow this scale method of division. They rather present a list of nine strategies: loan, calque or literal translation, explicitation, substitution, transposition, lexical recreation, compensation, omission and addition (2014, p. 202). Although these taxonomies contain similarities, each of them has strategies that the others lack. A more comprehensive classification of CRs and their translation strategies is proposed by Ranzato (2013) and adopted as the model of analysis in the present study. An account of this model is given in the next paragraphs.

Ranzato (2013) proposes a taxonomy of CRs and their translation strategies that is designed as "a practical tool for analysis" (p. 79). Her classification of CRs is based on the relationship between cultures. In that, she is affected by Pedersen's transculturality (2005), discussed earlier, but her typology largely takes the point of view of the TA. Her classification of translation strategies is based on that of Cintas and Remael (2007) that is mentioned earlier in the present study.

Ranzato divides CRs, or culture-specific references (CSRs) as she calls them, into two major categories, namely realistic references and intertextual references, each of which has its own subcategories. Any of these subcategories can be either verbal or nonverbal CRs, or synchronous or asynchronous CRs. Instead of the more common classification of CRs into lexical sets, Ranzato's classification is conceptual, "tak[ing] into account the nature of CSRs within the relationship between TT and ST and from the exclusive point of view of the TC" (2013, p. 79). For Ranzato, this relationship between the TC and the ST should be the basis on which CRs are classified. For, a CR is not problematic because it belongs to a certain lexical set; it is problematic because it exists in the ST, but does not exist in the TC, or exists in the TC with a different status or value. Hence, the classification of CRs should not be lexically based. It should be based on the relationship between the ST and the TC.

Although Pedersen (2005) takes this relationship into account and classifies CRs according to their degree of transculturality, it is not quite clear whether the basis of this classification is anything but the researchers' or translators' own assessment of how familiar a CR is to the $\mathrm{SA}$ and the TA. Therefore, their judgement can be very riskily subjective since it is based on their own point of view, which might be different from that of the TA, that are the actual audience the translation is presented to. Objectively deciding the degree of familiarity or exoticism of a CR in a TC is extremely difficult. Therefore, Ranzato states that it is safer and less subjective to classify CRs from the point of view of the TA 
The Effect of Cultural Distance on Translating Cultural References in al-Zayyat's The Open Door (1960)

and based on the relationship between the TC and the other cultures involved in the translation, whether the SC or any other culture, as her proposed categories show. Taking the space between cultures into consideration and attempting to deal with it as objectively as possible make Ranzato's classification a suitable tool of analysis that effectively serves the objective of this study.

Ranzato starts her classification by differentiating between realistic and intertextual references. Realistic references are references to everything that is non-fictional, i.e. persons, food, institutions, etc. that exist in reality. They are subdivided based on the CR's culture of origin. Intertextual references include implicit and explicit allusions to any artistic text whether literary or audiovisual. Source culture references, the first subcategory of realistic references, include references strictly belonging to the SC, no matter how popular they are in other cultures including that of the TA. In other words, a reference belonging to the SC may be well known by some members of the TC because of their own knowledge, their interest in the SC, films and so on. However, this reference will be categorized as a $\mathrm{SC}$ reference as long as it does not have "a direct, provable, objective bond with the TC" (Ranzato, 2013, p. 82). An example is "Harrods", the famous department store in London. "Harrods" is regarded as a SC reference, in the case of translating a British English text for the Egyptian Arabic-speaking audience. It has not opened a branch in Egypt and does not have a concrete bond with the Egyptian culture; yet, many Egyptians may make connections and associations related to its previous Egyptian owner Muḩammad al-Fāyid.

The second subcategory, intercultural references, involves references that originally belong to the SC but are incorporated in the TC by one degree or another, which makes members of the TC consider them part of their own culture. Such references are related to the TC in "a measurable and proven" way that is more concrete than mere associations or connections related only to the SC (p. 83). Examples include brand names that are sold in both the SC and the TC such as "McDonald's" (p. 83) and "Pepsi". Intercultural references are also those that are part of both cultures, the SC and the TC, regardless of their origin. Ranzato suggests that this origin can sometimes be uncertain, providing "Santa Claus" as an example (p. 83).

Third culture references contain references that neither belong to the SC nor to the TC, but rather to a third culture. Such references are problematic because they presuppose a certain degree of familiarity on the part of the SA with references belonging to a third culture, while the 
TA may not be as familiar with this third culture. This highlights the importance of measuring the distance between the TC and the ST reference from the TA's perspective. The last subcategory of realistic references is target culture references. It involves references that are somewhat exotic in the SC, yet they are not exotic in the TC as they are actually part of it. The problem here is caused by the effect such references exert on the SA, which is probably different from that exerted on the TA, being very familiar with the reference while it is supposed to give a foreign colour to the text.

The second major category in Ranzato's classification of CRs is intertextual references. Ranzato presents intertextual references more clearly and independently than the other taxonomies, acknowledging their importance and their difference from other types of CRs. Such references relate the ST to other texts through quotations and allusions, relying on the audience's knowledge of such texts and their ability to connect the current text to them. This may require a specialized knowledge on the part of the audience to be able to make such connections. This increases the possibility of such CRs to be less identifiable by the TA members, or at least some of them. Intertextual references are subdivided into overt intertextual allusions, covert intertextual allusions and intertextual macroallusions.

Overt intertextual allusions include direct quotations from other texts as well as a direct mention of titles of films, songs, TV shows, etc. Adopting the point of view of the TA, a translator may find that the TA are unlikely to identify the CR. Moreover, even when a reference is made to a text that is very popular in the TC, the translator may feel obliged to use the official translation of the CR that already exists in the TC, which may cause the peculiar meaning of this reference in the present text to be lost. On the contrary, covert intertextual allusions are implicit references to other texts. They are as problematic as overt intertextual allusions mainly for the same reasons. Additionally, covert intertextual allusions may even be too vague to be conveyed to the TT with no change. Intertextual macroallusions refer to the case when the concept of a text as a whole is based on or is an allusion to another text(s). This can be done overtly by explicitly stating from the beginning of the text that it is based on a certain text, or be done covertly by giving the audiences hints and allowing them to figure out the text(s) alluded to on their own.

As mentioned earlier, all those subcategories of realistic and intertextual references can be either verbal or nonverbal, or synchronous or asynchronous. It is true that nonverbal cultural references can sometimes be found in written texts, e.g. novels including multimodal 
The Effect of Cultural Distance on Translating Cultural References in al-Zayyat's The Open Door (1960)

material such as paintings and photographs besides the written text. However, such references are mainly audiovisual, and can be visual, acoustic or both. Since the present study analyses a novel that is purely verbal, nonverbal references are not used in this analysis.

Any of the previously discussed types of realistic and intertextual references can also be synchronous or asynchronous cultural references. CRs have primarily been perceived and discussed by scholars as specific to a certain culture located in a certain place or geographical area. Nevertheless, Ranzato (2013) argues that CRs are also located in a certain time. Therefore, CRs are not only culture specific, they are also time specific. A text may include CRs that belong to a time different from that in which the audience live. In this case, they are asynchronous CRs, and may be unidentifiable even by some of the SA members because of the time gap. Naturally, such references are much less recognized by the TA, as they belong not only to a relatively remote culture, but to a relatively remote time as well.

Based on a conceptual rather than a lexical division, Ranzato's classification of CRs is generally more comprehensive than the others referred to earlier in the study, e.g. Newmark (1988), Aixelá (1996), Cintas and Remael (2007) and Guerra (2012). It can encompass as many CRs as possible no matter what lexical group a reference belongs to. As indicated earlier, adopting the point of view of the TA makes this classification more objective than the others previously discussed here, e.g. Pedersen (2005). It is also worth noting that it may seem that the two major categories of realistic and intertextual references overlap; however, their different nature makes them largely separate. It is true that intertextual references may be source culture, target culture, third culture or intercultural references, which seems to create the overlap with realistic references. Nevertheless, the origin of intertextual references is considered of secondary importance. The primary importance in this category is attached to the relationship created between two texts and its impact on the audience. For instance, when a text alludes to or quotes from Hamlet, it is not mostly making a reference to the British culture, being the origin of the writer, nor to the Danish culture, being that of the character. It is rather making a reference to and building a relationship with the text itself. These features of intertextual references make them distinct from realistic references which are mainly based on the culture of origin.

Ranzato (2013, pp. 102-114) also proposes a taxonomy of strategies for translating CRs. She presents it to deal with CRs in 
dubbing. However, this classification is applicable to written translation as well. It is made up of eleven strategies, those are loan, official translation, calque, explicitation, generalisation by hypernym, concretisation by hyponym, substitution, lexical recreation, compensation, elimination and creative addition. Loan is to repeat the CR of the ST as it is with no change in the TT. For a long time, loan has been viewed as a foreignising strategy that introduces a colour of exoticism to the TT. Such opinion is adopted by Vinay and Darbelnet (1995) and Dickins et al. (2002), for example. Ranzato (2013) questions this opinion and provides evidence from her corpus, arguing that "foreignisation is in fact not necessarily the natural result of this strategy" (p. 103).

The second strategy, official translation, means to use the translation that already exists in the TL by means of previous translations. In this case, the translator is involved in a research process of some level of intensity in order to find the official translation of a term that is recognized in the TC. Calque is the literal translation of a CR. It can also be used to refer to the literal translation of possibly long CRs, such as allusions and quotations. Calque is followed by explicitation in Ranzato's taxonomy. It refers to presenting a definition of the CR through explaining it or adding information to it. This definition is mainly, but not always, accompanied by keeping the CR itself in the TT. Explicitation is also when the CR term is replaced by another term that is used for the same CR; however, it is more popular or more generic. An example is replacing "Frisco" by "San Francisco" in translation (Ranzato, 2013, p. 106).

Generalisation by hypernym does not involve adding information to the CR, yet it means to replace the CR as a whole with a hypernym. This is not necessarily a single word. A hypernym can be one or more words that have a more general meaning than the term in question. On the other hand, concretisation by hyponym is to replace a general term with a more specific one, using a hyponym. The example presented by Ranzato is rendering "British" as "English" (2013, p. 107). Substitution refers to the replacement of a CR by another one, shorter or longer, to conform to dubbing technical constraints such as lip synch and isochrony. This strategy is also employed due to cultural concerns, i.e. replacing a CR that may not be identified by the TA with a more familiar one (Ranzato, 2013). This actually makes the strategy appropriate not only for dubbing but for other forms of translation as well, including written translation.

Lexical recreation generally involves introducing a neologism in the TT, mainly because one is presented in the ST. While compensation refers to the case in which a translation loss occurring at a certain point is 
The Effect of Cultural Distance on Translating Cultural References in al-Zayyat's The Open Door (1960)

compensated for in another point in the translation, elimination is the case where a CR is not rendered at all to the TT. Elimination, for Ranzato, also includes translating a CR by means of a paraphrase that is suitable for the context but does not convey the meaning of the original CR itself. This is because it causes the CR to be lost without even being replaced by another. The final strategy proposed in this taxonomy is creative addition. She describes it as "a form of authorial intervention" by the translator (Ranzato, 2013, p. 113). It is closer to rewriting than to translation, involving the addition of an expression or a CR in the TT that is not included in the ST.

This classification of translation strategies is more comprehensive than many of the previous taxonomies mentioned earlier in this study, such as Newmark (1988) and Dickins et al. (2002). It provides a wider variety of strategies; hence, it covers a larger number of the cases that may be encountered in translation analysis. It is true that Ranzato presents this taxonomy within the discussion of dubbing. Nonetheless, reviewing its strategies reveals that it can be largely applied to other forms of translation such as written translation, and it is employed in the present study for this purpose.

The data analysed in this study is extracted from an Arabic novel and its English translation. The novel is Latifa al-Zayyat's الباب الدفتوح (alBāb al-Maftūh h), first published in 1960. The edition used in this study is the $2^{\text {nd }}$ edition published in 2015. It is translated into English as The Open Door by Marilyn Booth in 2000. The study uses the edition published in 2002. The novel depicts and discusses the Egyptian culture and life events in the 1940s and 1950s. However, the major part of the novel is concerned with the pre-1952-revolution period. al-Zayyat's novel takes the point of view of a female member of the middle class in Cairo in portraying the life events of this era. This makes the text rich with a broad range of CRs. The novel goes deeply into the social, political, historical and cultural Egyptian context at the time. Moreover, the register of the dialogue in the novel is Egyptian colloquial Arabic. Consequently, most of the CRs belong to the SC, i.e. the Egyptian culture. This raises translation issues, especially due to the relatively wide distance between the SC and the TC. These features characterizing the text serve the purpose of the study.

Selected examples of CRs and their translation collected from the abovementioned texts represent the data analysed in the study. These examples are selected based on the definitions of CRs discussed earlier, and on the adopted model of analysis, i.e. Ranzato (2013). This data is 


\section{Weaam Sobhy Mohamed Afifi}

analysed following a descriptive qualitative approach. The selected CR examples are arranged in the analysis based on the translation strategies proposed in the model of analysis. The qualitative analysis of these examples attempts to explain the ST reference itself and its status and connotation. It also assesses the strategy used and its effect on conveying the meaning and the cultural features to the TA. The analysis tries to identify how far the distance between the SC and the TC influences how the translation is done, and to figure out the translator's motive for choosing the translation strategies used.

Ten out of Ranzato's eleven translation strategies are employed in the translation of The Open Door. Only lexical recreation does not occur in this translation, because the ST does not introduce any neologisms. Following are examples of the other ten strategies.

The first strategy is loan. As mentioned earlier, the ST of the novel is full of CRs, most of which belong to the SC. Ranzato claims that loan is mostly used when the CR term exists in the TC and is familiar to its audience, which results in domestication rather than foreignization. However, the opposite is true in The Open Door, where many SC, as well as third culture, references that are not part of the TC are translated using loan. Following is an example of this case.

Example 1

\begin{tabular}{|c|c|}
\hline ST & TT \\
\hline 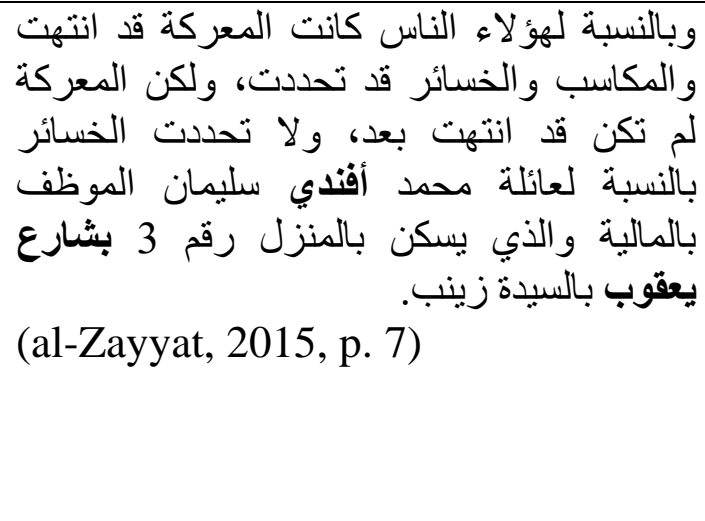 & $\begin{array}{l}\text { For those talking excitedly on the street } \\
\text { the battle had ended. Final gains and } \\
\text { losses had been tallied. But the battle } \\
\text { had not yet ended, nor had any sums } \\
\text { been figured, for the family of } \\
\text { Muhammad Effendi Sulayman, civil } \\
\text { servant in the Ministry of Finance and } \\
\text { resident of No.3 Ya'qub Street in the } \\
\text { neighborhood of Sayyida Zaynab. } \\
\text { (Booth, 2002, p. 5) }\end{array}$ \\
\hline
\end{tabular}

In the novel, Muhammad Effendi Sulayman is the father of Layla, the protagonist, and Mahmud. In this incident in the novel, Mahmud has taken part in a mass demonstration held against Britain, the occupier of Egypt at the time, in which many were injured and killed. He has not returned home yet although the demonstration has ended hours ago, and his family does not know his whereabouts or what has happened to him. At that time, Egypt had also been under the long rule of a Turkish dynasty. This has led to the use of several Turkish titles in Egypt. One of those titles is "Effendi". It is a third culture reference which means "Mister". It was used as a title for civil servants and other people of equal 
The Effect of Cultural Distance on Translating Cultural References in al-Zayyat's The Open Door (1960)

rank ('Umar, 2008). It was cancelled after the-1952 revolution that ended the Turkish dynasty rule in Egypt (al-Bannā, 2016). This also makes "Effendi" an asynchronous CR.

This title is familiar to the SA as it originally belongs to a culture that is close in distance to the SC for historical and geographical reasons. However, it is exotic to most TA members because of the rather wide distance between this third culture and the SC on the one hand, and the TC on another. Although it may be known by some of the TA members who are interested or specialized in matters related to the SC, this title is highly SC specific, and has not become part of the TC. The title "Effendi" is mainly related to countries located in the eastern area of the Mediterranean Sea, which include Turkey and Egypt (Merriam-Webster Online Dictionary, 2019).

The same applies to "Ya'qub Street", located at one of Cairo's neighbourhoods and familiar to its inhabitants. It is also worth noting that although the translator borrows the name of the neighbourhood where "Ya"qub Street" is located, she adds the word "neighbourhood" to it which is not mentioned in the ST. This makes it a case of explicitation rather than loan. Despite the exotic nature of the CRs presented in this example, the translator chooses to deliver them to the TT through loan. This creates a foreign effect, conveying some SC features and making the TA members feel that they are encountering an other who is located at a distance from them.

Loan is also used with other similar titles and names of local places repeated in the ST such as: "بانثا" (p. 9), "الخديو" (p. 14), "هانم" (p. 41) and "ميدان لاظوغلى"(p. 61), translated in the TT as " Pasha" (p. 7), "Khedive" (p. 11), "Hanim" (p. 33) and "Lazoghli Square" (p. 51) respectively. In some occurrences, the translator uses loan with CRs that represent more deeply embedded concepts in the SC. Such CRs are mainly associated with religion, reflecting how rooted it is in the SC and in the way of expression of the SA members. Examples of these CRs "و الله" (p. 154) "حرام" (p. 159) and "إن شاء الله" (p) 164). They are conveyed to the TT through loan, and further emphasis is added to them through italicization, being translated as "wallahi" (p. 79), "haram" (p. 130) and "in sha' Allah" (p. 133) respectively. Using loan with such references produces an air of exoticism for the TA. The translator may be attempting to introduce the SC to the TA and make them learn more about it. 
Weaam Sobhy Mohamed Afifi

\section{Example 2}

In some cases, loan is employed with CRs that are familiar to the TA as they belong to the TC. This is shown in the following example.

\begin{tabular}{|c|c|}
\hline ST & TT \\
\hline 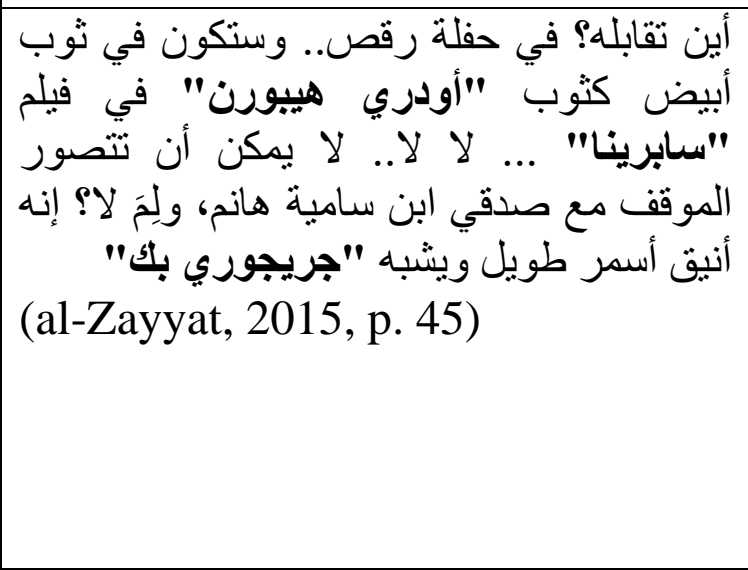 & $\begin{array}{l}\text { Mmm. But where would she meet him? } \\
\text { At a dance party, that was it. She would } \\
\text { be wearing a white dress just like the } \\
\text { one Audrey Hepburn had worn in } \\
\text { Sabrina. ... No! She could not imagine } \\
\text { such a scene unfolding with Sidqi, son } \\
\text { of Samia Hanim. But why not? He was } \\
\text { elegant. Dark. Tall. He looked a lot like } \\
\text { Gregory Peck, in fact. (Booth, 2002, } \\
\text { pp. 36-37) }\end{array}$ \\
\hline
\end{tabular}

In this example, Layla is a secondary school girl daydreaming about her Prince Charming. Here, two TC references and one intertextual reference are included in the ST. The TC references are the British actress "Audrey Hepburn" and the American actor "Gregory Peck", who took part in many classical Hollywood films in the 1950s and 1960s. The intertextual reference is an overt intertextual allusion to Sabrina, a title of a film named after its protagonist who is played by Hepburn. This reference creates a connection between al-Zayyat's novel as a text and this film as another. For the audience to know how the white dress Layla refers to looks like, they need to watch the film. In fact, this may pose a problem to some members of the SA, but not really to the TA as the film is part of their culture. Adopting the point of view of the TA makes using loan in translating these CRs a practical solution. However, because of the distance between the SC and the TC, loan also creates an effect on the TA that is different from that exerted on the SA. This is because while these CRs have a foreign impact on at least some of the SA, the opposite is true for the TA.

The second strategy employed in the TT is official translation. Although it uses the translation that is well-known by the TA, it does not necessarily convey similar connotations, as the next example shows. 
The Effect of Cultural Distance on Translating Cultural References in al-Zayyat's The Open Door (1960)

\section{Example 3}

\begin{tabular}{|c|c|}
\hline ST & TT \\
\hline 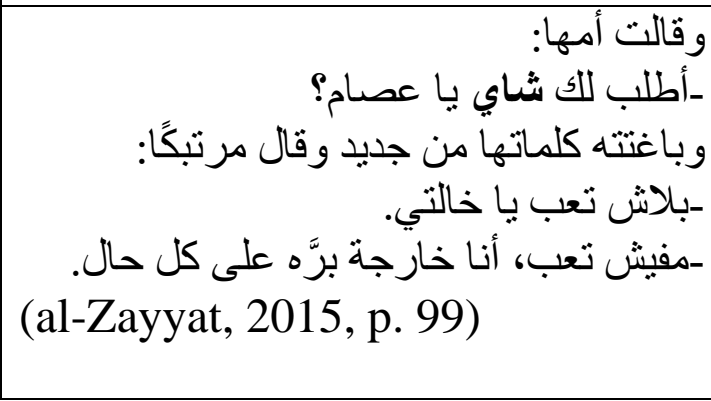 & $\begin{array}{l}\text { "I'll call for tea, Isam," said her } \\
\text { mother. Once again her words } \\
\text { caught him unawares and he spoke } \\
\text { in confusion. "Don't go to the } \\
\text { trouble, Aunt." } \\
\text { "It's no trouble, I'm getting up } \\
\text { anyway." (Booth, 2002, p. 83) }\end{array}$ \\
\hline
\end{tabular}

In this incident in the novel, Isam, Layla's cousin is visiting them and her mother is offering tea. The word "شاي" occurs numerous times in the ST and is translated in the TT as "tea". This is the official translation provided by dictionaries and used almost all the time. For instance, Baalbaki (2007) offers only the word "tea" as a translation for "شاي" in his Arabic-English dictionary. For many scholars, such as Newmark (1988), words like "tea" are considered universal words that do not normally create translation problems. This may be true since their official translations usually fulfil their universal function but they may not have the exact same referents. This is because what is sometimes seen as universal can have numerous cultural associations.

This applies to the word "tea", which is used as a designation of various and sometimes completely different entities in different cultures. In Egypt, for instance, "tea" refers to red or black tea; it is made by boiling tea-leaf powder or by adding hot water to it. It is mostly sugared, and milk or mint leaves are also commonly added. Tea enjoys a special status in Egypt, being considered the traditional drink of the country. A similar importance is given to tea in Britain, although it has different cultural and historical associations. Afternoon tea is a tradition, and tea is also usually served with sugar and milk. High tea and low tea are two forms of afternoon tea, originally related to the social classes of the British society (Dubrin, 2012). In the USA, tea is also popular; however, Americans have a strong tendency to iced tea more than to hot tea (Ferdman, 2014). Additionally, the word "tea" refers to other hot drinks made by pouring boiling water to herbal leaves, such as peppermint, cinnamon, chamomile, ginger, etc. (Hornby, 2006). In the Egyptian Arabic culture, these types of hot drinks are not referred to by the word "tea"; they are rather referred to as "herbs" (in Arabic, أعشاب). Hence, the words "شابي" and "tea" provoke different associations in the minds of the SA and the TA, mainly due to the distance between their cultures. The 


\section{Weaam Sobhy Mohamed Afifi}

use of official translation delivers the functional meaning of the ST word, but leads to the loss of its connotations.

A similar case is "عيش" (p. 22), the designation Egyptians use to refer to bread instead of the standard Arabic name "خبز" ('Amīn, 2013). The word "عيش" literally means "living" or "life", which mirrors how "عيش" much esteem Egyptians have for this food item. The designation appears in the TT in its official translation "bread" (p. 16). Like the case is with "شاي" and "tea", "عيش" and "bread" may very well have distinct referents in the SC and the TC. This makes the official translation "bread" convey the universal meaning of "عيش" without expressing its cultural associations. Although the translator has the ability to include notes clarifying such connotations, this mainly depends on her assessment of how significant these CRs are in the text. Her choice of official translation indicates that she gives priority to making the reading smooth to the TA in these cases, rather than interrupting them with such notes.

The third translation strategy is calque, and it is frequently applied in the TT to translate proverbs and similar expressions, especially those belonging to the SC. Following are two examples representing this case.

\section{Example 4}

\begin{tabular}{|c|c|}
\hline ST & TT \\
\hline 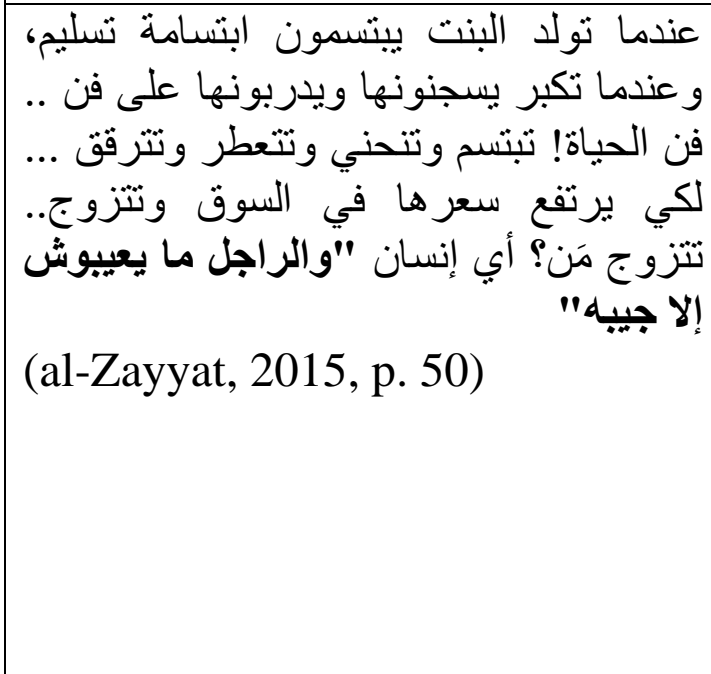 & $\begin{array}{l}\text { Whenever a girl was born, they } \\
\text { smiled in resignation. When she } \\
\text { began to grow up, they imprisoned } \\
\text { her, and trained her in the art - yes, } \\
\text { the art of - life! They taught her to } \\
\text { smile, to yield to others, to wear } \\
\text { perfume, to exude sympathy. ... so } \\
\text { her price would go up in the market } \\
\text { and she could marry. Marry whom? } \\
\text { Any old person; after all, "the only } \\
\text { thing that can shame a man is his } \\
\text { pocket." (Booth, 2002, p. 41) }\end{array}$ \\
\hline
\end{tabular}

In her self-talk, Layla is criticizing the customs of her society at that time that treated girls as goods in a market that can be bought by the man who "و الر اجل ما يعيبوش "إلا جيبه, translated in the TT as "the only thing that can shame a man is his pocket." This is a SC reference that means that what shames a man is his inability to financially support his family (Taymūr, 2014), or to provide it with a financially comfortable life. The mention of this proverb confirms the social concept that the richer a man, the better he is as a groom. 
The Effect of Cultural Distance on Translating Cultural References in al-Zayyat's The Open Door (1960)

Additionally, using proverbs is a trait of the mother's character and language. She, along with Layla's father, represents the blind belief in social traditions. Therefore, keeping the proverb in translation is essential, especially that a major theme in the novel is the achievement of freedom from those harmful traditions that hold the society back. Booth translates this proverb literally, keeping its form. The words used in translation and the context make it easy for the TA to understand the meaning of the proverb. The one thing that is missing in translation is that the TA may not be able to recognize that this is actually a proverb in the SC, and may not be able to identify its degree of popularity. Such aspects are part of the SC features, and not conveying them is considered a translation loss. This is especially because of the association between the recurrent use of proverbs and the mother's character in the novel, and what this association symbolizes. The SA, on the contrary, can identify such aspects and connotations with relatively great ease since this proverb is part of their own culture, unlike the TA. This means that the status or value of this $\mathrm{CR}$ in the $\mathrm{SC}$ is not conveyed to the TT as a result of the cultural gap between the SC and the TC.

Example 5

\begin{tabular}{|c|c|}
\hline ST & TT \\
\hline 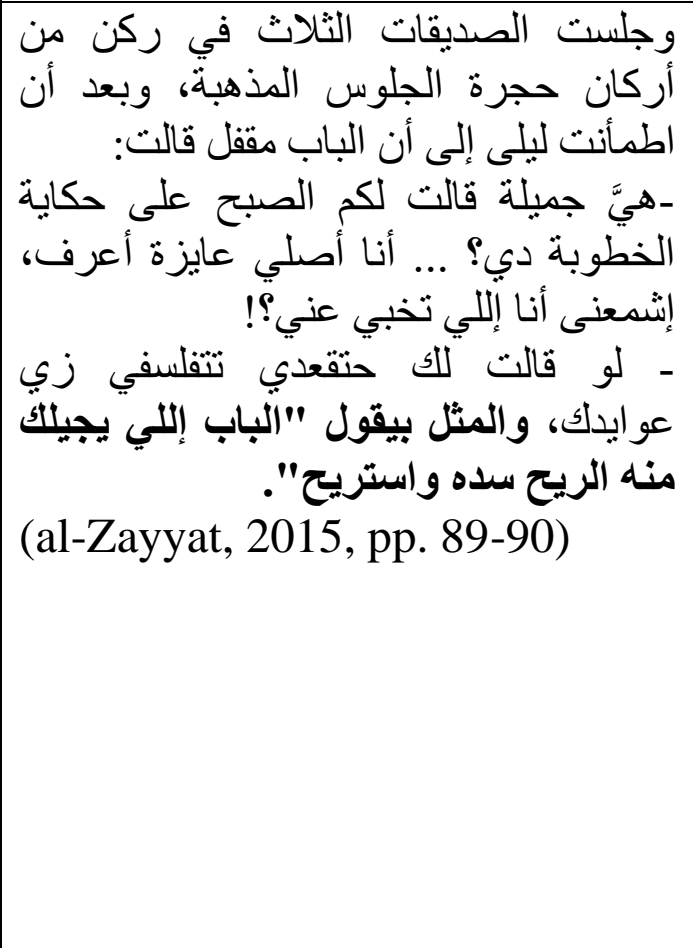 & $\begin{array}{l}\text { So the three friends sat down in a } \\
\text { corner of the gilt-furnished sitting } \\
\text { room. Layla made sure the door was } \\
\text { closed and only then spoke. } \\
\text { "Did Gamila tell you this morning } \\
\text { about this engagement business?" ... } \\
\text { "I mean, I want to know, why was it } \\
\text { hidden from me? Why me, in } \\
\text { particular?" } \\
\text { "Gamila knew that if she said } \\
\text { something to you directly, you'd } \\
\text { have sat there philosophizing, going } \\
\text { on and on as you always do. The } \\
\text { proverb, you know, says, 'Close } \\
\text { the door from whence the wind } \\
\text { comes and rest."' (Booth, 2002, pp. } \\
\text { 75-76) }\end{array}$ \\
\hline
\end{tabular}

Here, Layla and her friends are discussing the news about the engagement of Gamila, Layla's cousin. She is getting engaged to a rich man who has a villa and a nice car, but who is much older than her. Since she knows 


\section{Weaam Sobhy Mohamed Afifi}

Layla opposes this kind of marriage that her society welcomes, she has avoided telling her this news directly. She expects that Layla would lecture her about how unacceptable this marriage is. Hence, she decides to apply the abovementioned proverb which means: Avoid whatever harms you by completely blocking its source and rest (Taymūr, 2014). The translator conveys this SC reference to the TT through calque. Unlike example 4, this proverb is preceded in the ST by words that indicate its status as a well-known saying. This assists the TA in identifying one of the features of the SC and recognizing the figurative sense of the words this saying uses. Here, the ST itself helps the TT reduce the gap between the two cultures under translation.

Explicitation represents the fourth translation strategy and it is recurrently employed by the translator of The Open Door. It is often used in the TT with SC references, including concepts, food items, place names and expressions. The following examples illustrate that different forms of explicitation are utilized in an attempt to clarify such CRs to the TA.

\section{Example 6}

\begin{tabular}{|c|c|}
\hline ST & TT \\
\hline 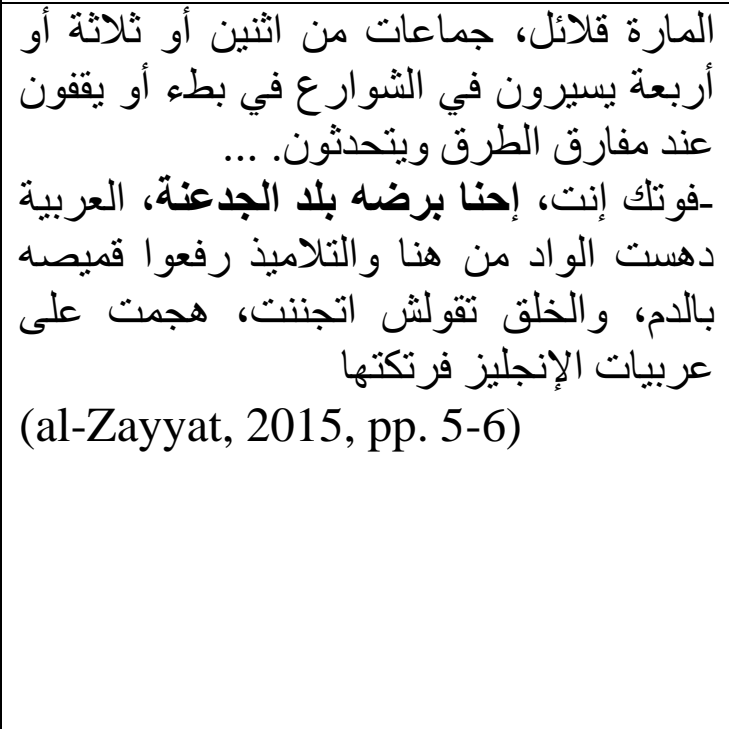 & $\begin{array}{l}\text { The few civilians in sight walked } \\
\text { slowly in the streets or stood at } \\
\text { intersections, knots of two, three, } \\
\text { or four engaged in conversation. ... } \\
\text { "Don't forget we Egyptians are } \\
\text { brave - a country of tough guys. } \\
\text { The tank crushed the lad and right } \\
\text { away the students raised his shirt } \\
\text { high to show everyone; there was } \\
\text { blood all over it. Then the crowd } \\
\text { just went mad. They attacked the } \\
\text { English tanks and pulled 'em apart } \\
\text { (Booth. } 2002 \text {, pp. 3-4) }\end{array}$ \\
\hline
\end{tabular}

Here, the novel describes the events of the mass demonstration held against the English and referred to in example 1. This description is presented through people who are still in the streets after the demonstration has ended. One of them depicts Egypt as the country of "الجدعنة". This is a reference to a concept that is highly specific and deeply rooted in the SC. The CR of "الجدعنة" carries multiple meanings that include chivalry, morality, willingness to help in hard times (al-Juharī, 2007), bravery and strength. These meanings directly come to the minds of the SA when they hear or read the word "الجدعنة without need for 
The Effect of Cultural Distance on Translating Cultural References in al-Zayyat's The Open Door (1960)

further elaboration, unlike the case with the TA. The translator here attempts to define this SC concept through providing an explanation of it, describing Egypt as the country of "brave" and "tough guys". Nonetheless, this explanation caters for only some of the senses of this concept, while others are lost in translation.

\section{Example 7}

\begin{tabular}{|c|c|}
\hline ST & TT \\
\hline 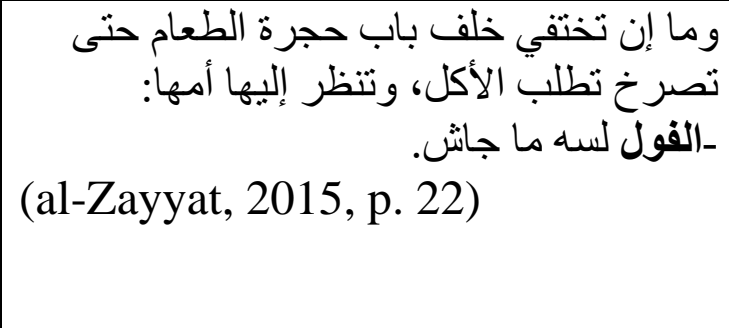 & $\begin{array}{l}\text { She disappeared into the dining } \\
\text { room and immediately demanded } \\
\text { food in a loud voice. Her mother } \\
\text { glared at her. "The ful-beans for } \\
\text { breakfast haven't arrived yet" } \\
\text { (Booth. 2002, pp. 15-16) }\end{array}$ \\
\hline
\end{tabular}

The CR "الفول" is a reference to a food item that Egyptians cherish most. It is an essential item for almost all of them regardless of their social class and they prepare it in various ways. It also represents their traditional breakfast ('Amīn, 2013). One of the forms of explicitation is to borrow a $\mathrm{CR}$ and add an explanation to it. The translator's choice of this explicitation form here is significant. She decides to borrow the word "ful", italicize it and add information that works as an explanation of it, introducing the TA to what is known for the SA without being said. Borrowing here attracts attention to this SC reference and lays the required emphasis on such an important food item for Egyptians. At the same time, the translator adds enough information to the borrowed word, clarifying that it is a type of beans. This prevents the CR from being too vague for the TA. Furthermore, adding that this is the ful-beans "for breakfast", although it is not there in the ST, gives the TA a hint that this is the usual breakfast for most of the SA members. The translator may intend to create a balance between producing a similar effect on the TA to the one the ST has on its audience, and keeping the exotic colour by introducing the TA to the local features of the SC. This is an attempt to narrow the gap between both cultures. The same form of explicitation is employed by the translator in the following example, yet in a different manner.

\section{Example 8}

\begin{tabular}{|c|c|}
\hline ST & TT \\
\hline 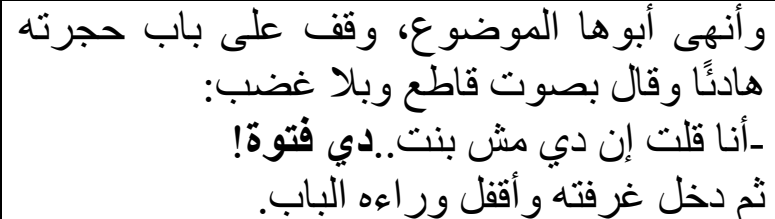 & $\begin{array}{l}\text { Her father, appearing in the } \\
\text { doorway to his room, brought } \\
\text { the matter to a close in his } \\
\text { unruffled way, his voice firm but }\end{array}$ \\
\hline
\end{tabular}


(al-Zayyat, 2015, p. 24)

empty of anger. "I told you before that this one's no ordinary girl. She's a fitiwwa, a real bull in a china shop." He turned, went back into his room, and shut the door behind him. (Booth, 2002, p. 18)

In this incident in the novel, Layla's mother asks her to hand her the alarm clock which falls off Layla's hands and its glass gets broken "just like everything in the house, in fact. Everything her fingers picked up" (Booth, 2002, p. 18). Layla is a clumsy eleven-year-old girl; she is not always the quiet well-mannered girl her parents expect her to be. Similarly, her parents usually react in an exaggerated manner, with the mother telling Layla that God has made her "a real problem-child" and her father calling her a "fitiwwa" (Booth, 2002, p. 18). The translator's decision to keep the word "fitiwwa" and transfer it to the TT is interesting. A fitiwwa, as pronounced in Egyptian colloquial Arabic or futuwwa in standard Arabic, is a strong man who imposed his power and protection over a neighbourhood in return for money. It also carries the sense of a gangster or a criminal. Additionally, futuwwa means chivalry, generosity, bravery and eagerness to defend and help others ('Umar, 2008, p. 1672). These contradictory senses reflect how historically and culturally loaded this CR is.

In the history of Islam, from the tenth to the fourteenth century C.E., futuwwa formed some kind of a social institution in various Islamic countries. The members of this institution, called fityan, had certain gathering places and mainly cared about helping others and showing hospitality to strangers. Futuwwa gained a politically high position when "the Abbasid caliph in Baghdad, al-Nasir li-Din Allah (r. 1180-1225) declared himself the head of all the futuwwa lodges in Iraq and elsewhere" (Irwin, 2004, p. 162, emphasis in original). This form of futuwwa moved from Abbasid Iraq to Mamluk Egypt, but almost ceased to exist by the fifteenth century (Jacob, 2007, p. 694). Afterwards, the negative connotations of futuwwa started to emerge and by the nineteenth and early twentieth centuries, futuwwa became associated with a strong man imposing his power over a neighbourhood. It turned into a system in Cairo and other Egyptian cities by which every futuwwa, or rather fitiwwa, dominated a certain neighbourhood and protected it from the attacks of the fitiwwas of other neighbourhoods who usually sought to bring more districts under their control, aiming for a bigger share of protection fees (Jacob, 2007). Of course, this phenomenon does not exist in modern-day Egypt and has been so for long decades. 
The Effect of Cultural Distance on Translating Cultural References in al-Zayyat's The Open Door (1960)

Describing Layla as a fitiwwa here simply means that she has a tough attitude that ordinary girls, from her father's point of view, do not have. However, the translator still chooses to borrow the word with all its exoticism and use it in the TT. This may indicate that there is an intention to convey as much as possible of the SC to the TA even if this may make the reading of the novel less smooth.

However, explicitation necessarily includes an explanation of the borrowed word. Interestingly, the translator gives this explanation by introducing a TC idiom, which is an embedded use of the strategy of creative addition within explicitation. Creative addition involves adding a CR in the TT that is not included in the ST. Here, the translator adds the idiom "a bull in a china shop", which means "a person who is careless, or who moves or acts in a rough or awkward way, in a place or situation where skill and care are needed" (Hornby, 2006, p. 188). It also refers to a person who is "extremely clumsy" (Ammer, 2013, p. 61). Adding this idiom to the borrowed word "fitiwwa" successfully conveys the intended meaning, makes it more comprehensible to the TA, and makes the borrowed CR less of an obstacle in the way of TA's understanding of the text. Nevertheless, it is doubtful that the TA will be able to identify the other cultural connotations of such a rich CR that belongs to another culture with a far different historical and social background.

\section{Example 9}

\begin{tabular}{|c|c|}
\hline ST & TT \\
\hline 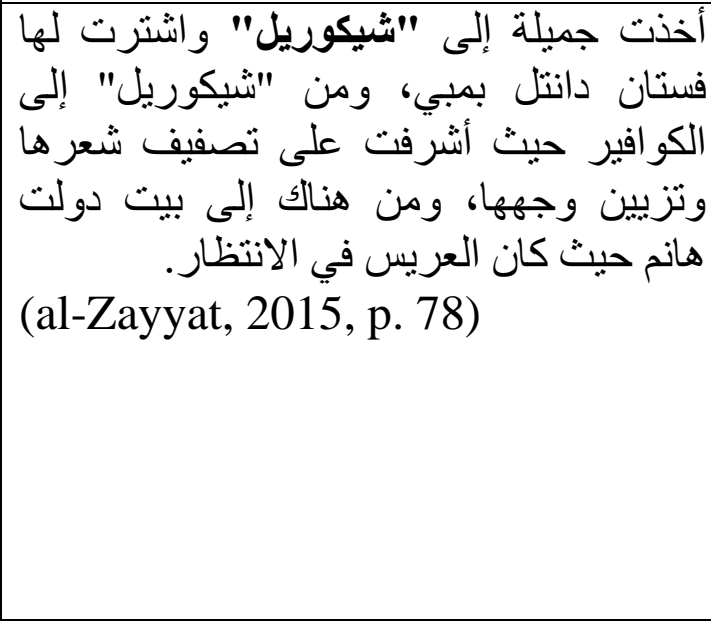 & $\begin{array}{l}\text { She took Gamila to Cicurel, the } \\
\text { department store downtown } \\
\text { where all the best people went. } \\
\text { She bought her a dress of pink lace. } \\
\text { From Cicurel they went on to the } \\
\text { coiffeur, where Dawlat supervised } \\
\text { Gamila's new hairdo and makeup. } \\
\text { From there they went to Dawlat } \\
\text { Hanim's home, where the } \\
\text { bridegroom was waiting. (Booth, } \\
\text { 2002, p. 66) }\end{array}$ \\
\hline
\end{tabular}

In this example, the translator borrows the name of the store "Cicurel", and provides a description clarifying what it is and its status in the Egyptian society at the time. In addition to presenting this explanation inside the TT, Booth mentions Cicurel in her introduction to the translation. She states that "les Grands Magasins Cicurel et Oreco was owned by a prominent Cairo family of Jewish Egyptians, and twice 


\section{Weaam Sobhy Mohamed Afifi}

rebuilt by the Egyptian government" (2002, p. xxii). She adds that it was burned in The Cairo Fire, a massive fire that took place in Cairo on January 26, 1952. These two explanations inside the text and in its introduction offer the TA the social, historical and cultural background on this SC reference. This helps in mitigating the foreignness of this $\mathrm{CR}$ for the TA and in filling part of the distance between their culture and the SC. Example 10

\begin{tabular}{|c|c|}
\hline ST & TT \\
\hline 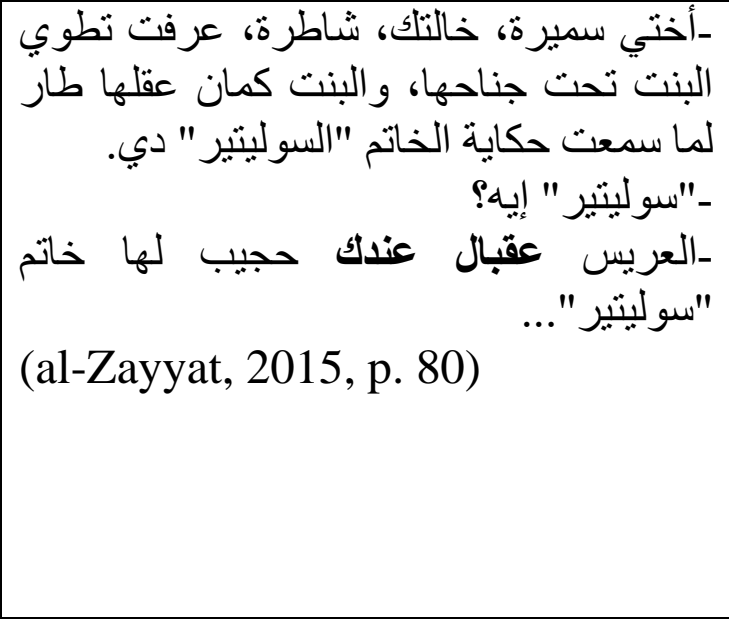 & $\begin{array}{l}\text { "My sister Samira, your aunt, } \\
\text { she's so smart! She knows how to } \\
\text { keep that girl under her wing. And } \\
\text { the girl as well - her mind went to } \\
\text { pieces when she heard this talk } \\
\text { about the solitaire ring." } \\
\text { "What solitaire?" } \\
\text { "The groom - may your future } \\
\text { hold the like - is going to get her a } \\
\text { solitaire ..." } \\
\text { (Booth, } 2002, \text { p. } 68 \text { ) }\end{array}$ \\
\hline
\end{tabular}

In this incident, Layla's mother is telling her the recent news about Gamila's engagement to the rich groom. She wishes her a similar marriage, using the SC idiom "عقبال عندلك a ". This expression is usually used by someone who is celebrating a happy occasion such as achieving success, getting married, having a baby, etc. It is used by this person or other members of the family, expressing that they wish their addressees a similar pleasant occasion in the future (al-Juharī, 2007; 'Umar, 2008). In translation, Booth explicates the meaning of this SC expression and puts it in a form that clarifies its use as a wish. However, as in example 4, the TA may well get the meaning of this CR but may not be able to realize that it is a fixed expression frequently used in similar contexts in the SC.

Fifth, generalisation by hypernym is a strategy that usually produces a translation that is easy for the TA to understand. Nonetheless, its effect in regard to transferring the connotations of a SC reference to the TT is not always a positive one. This is revealed in the next example.

\section{Example 11}

\begin{tabular}{|c|c|}
\hline ST & TT \\
\hline 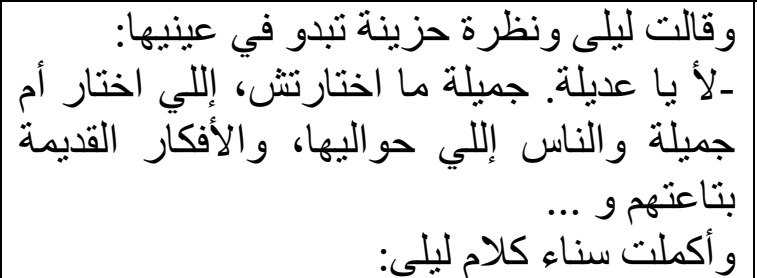 & $\begin{array}{l}\text { They could not miss the distress } \\
\text { in Layla's expressive eyes. "No, } \\
\text { Adila, no. Gamila didn't choose. It } \\
\text { was Gamila's mother who decided, } \\
\text { and the folks around her, and all }\end{array}$ \\
\hline
\end{tabular}


The Effect of Cultural Distance on Translating Cultural References in al-Zayyat's The Open Door (1960)

\begin{tabular}{|c|c|}
\hline 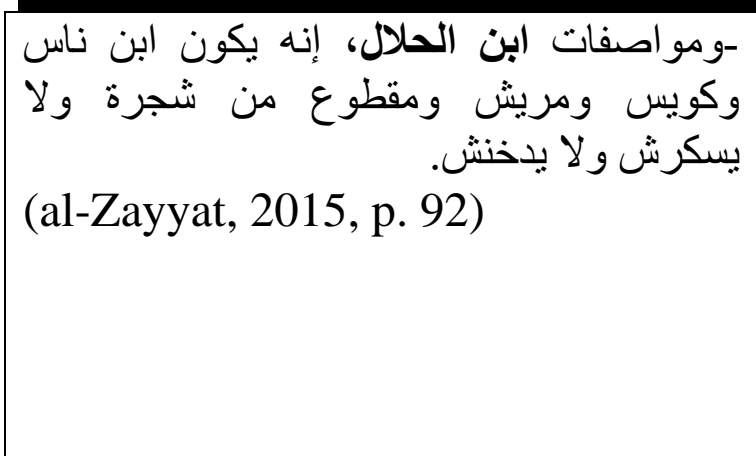 & $\begin{array}{l}\text { their tired old ideas. And -" } \\
\text { Sanaa chimed in. "- And the } \\
\text { goods on the lovely man. Son of a } \\
\text { good family, a real plum, seemly } \\
\text { and solid and reeking with money, } \\
\text { no relatives alive to come sniffing } \\
\text { around, doesn't get potted, doesn't } \\
\text { smoke." (Booth, 2002, pp. } 77-78 \text { ) }\end{array}$ \\
\hline
\end{tabular}

Layla and her friends Adila and Sanaa are discussing Gamila's marriage and the reasons that make her accept to marry such a groom who is not really suitable for her. These reasons include the qualities "ابن الحلال should have. This is another CR that has multiple meanings immediately understood by the SA, which creates a translation challenge in conveying it to the TA. From the religious aspect, the word "حلال " means permitted in Islam. Additionally, when someone is described as "هاب" without adding the definite article "ال" (i.e. the) to "حلال", it means that this person is thought to be kind, nice, polite, well-raised and generous, and to belong to a family whose members have those traits as well (al-Juharī, 2007). When the definite article "حلال" is in this expression, it is used in the SC to specifically refer to a groom, especially one who has such qualities. In translation, this expression is generalized into "the lovely man". The adjective "lovely" carries the meaning of "very kind, generous and friendly" (Hornby, 2006, p. 879). Nonetheless, this sense is broader than that of the SC reference and does not cater for its other meanings or its peculiar cultural connotations. Hence, while the SA get these multiple meanings of the expression, the TA only receive the general partial idea behind it.

The sixth strategy of concretisation by hyponym brings about a similar effect to that produced by generalisation by hypernym in the analysed TT. This is because both do not usually keep the cultural aspects of a SC reference in translation. This is shown in the following example.

Example 12

\begin{tabular}{|c|c|}
\hline ST & \\
\hline 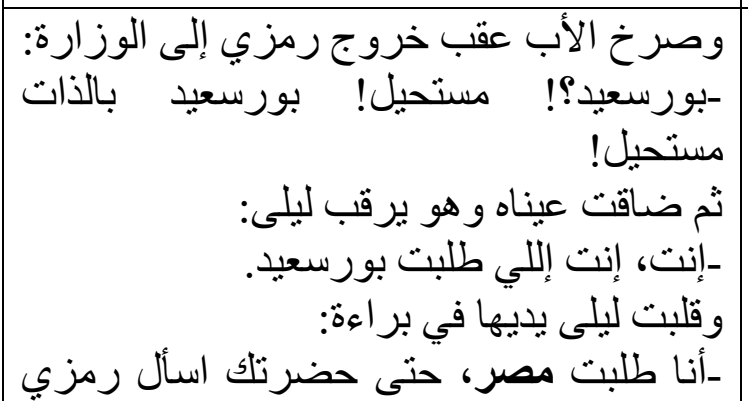 & $\begin{array}{l}\text { "Port Said?" her father shrieked } \\
\text { as soon as Ramzi had left to go to } \\
\text { the ministry. "Out of the question! } \\
\text { Port Said in particular - out of the } \\
\text { question." His eyes narrowed as he } \\
\text { stared at Layla. "You - it was you. } \\
\text { You asked for Port Said." }\end{array}$ \\
\hline
\end{tabular}


Weaam Sobhy Mohamed Afifi

(al-Zayyat, 2015, p. 406)

لما يرجع. Layla turned her palms up innocently. "I asked for Cairo. Sir, you can even ask Ramzi when he comes back." (Booth, 2002, p. 322)

By this stage of the novel, Layla has graduated university and she is engaged to Ramzi, one of the doctors who taught her in the Faculty of Arts. Although he has all the advantages that make him an excellent groom from the viewpoint of Layla's society, she does not like him. She has no admiration for his views, beliefs or the control he constantly exercises over her. In this instance of the novel, Layla's father and Ramzi learn that she has been appointed as a teacher in the city of Port Said against their will. However, they are not aware that she has intentionally asked for Port Said in her job application and she is pretending that she asked for "مصر".

In Arabic, "مصر" is the name of Egypt, but this is not its sole usage in the SC. Egyptians also usually use it to refer to their country's capital, Cairo (al-Juharī, 2007), especially when mentioned in relation to other Egyptian cities. This is the sense of "مصر" referred to in this example. This poses a translation problem that the translator handles by replacing "مصر" (i.e. Egypt) with its hyponym Cairo. This presents a pragmatic approach to the problem as it delivers the intended meaning to the TA, yet the special cultural side of this CR is not conveyed.

The use of the seventh strategy, substitution, in the TT is significant in relation to the distance between the SC and the TC. Substitution replaces the SC reference with a TC one, creating a translation that conforms to the norms of the TC. Adopting the viewpoint of the TA, this makes the TT read more naturally and smoothly. Conversely, if the translator insists on keeping each and every feature of the SC, the TT may be too foreign for the TA to read easily and smoothly. Moreover, other strategies that help keep the features of the SC references such as calque may sometimes produce an incomprehensible translation. This is mainly attributed to the distance between both cultures and is probably why substitution is recurrently employed in the TT, as displayed in the following examples.

\section{Example 13}

\begin{tabular}{|c|c|}
\hline ST & TT \\
\hline 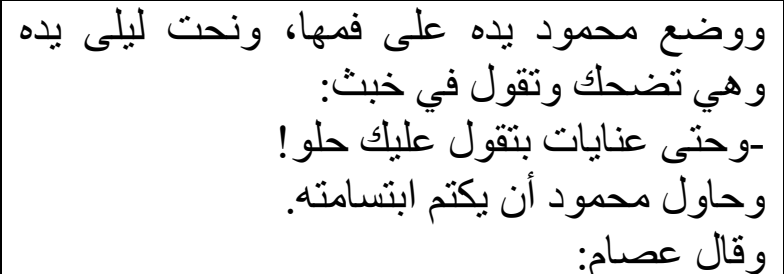 & $\begin{array}{l}\text { Mahmud put his hand over her } \\
\text { mouth. Layla pushed it away, her } \\
\text { laughter now a teasing voice. } \\
\text { "Even Inayat, she says you're } \\
\text { handsome!" At that, Mahmud }\end{array}$ \\
\hline
\end{tabular}


The Effect of Cultural Distance on Translating Cultural References in al-Zayyat's The Open Door (1960)

\begin{tabular}{|c|c|}
\hline 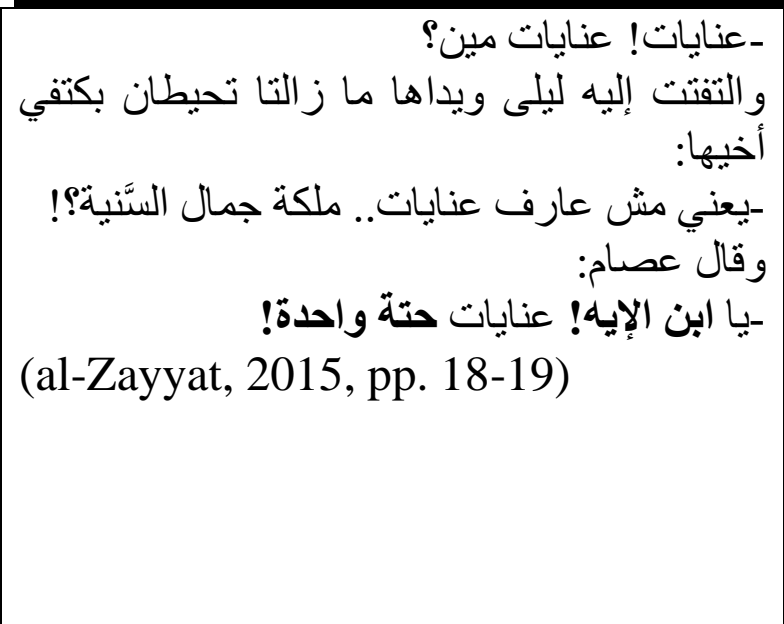 & $\begin{array}{l}\text { tried to conceal his smile. } \\
\text { "Inayat! Inayat who?" asked } \\
\text { Isam. Her arms still around her } \\
\text { brother, Layla turned to him. } \\
\text { "You mean you don't know who } \\
\text { Inayat is? She's the beauty queen } \\
\text { of the Saniya School!" } \\
\text { "Oh, her! You son of a gun!" } \\
\text { exclaimed Isam. "Inayat! She's a } \\
\text { knockout." } \\
\text { (Booth, 2002, pp. 13-14) }\end{array}$ \\
\hline
\end{tabular}

This example includes two SC idioms that Booth replaces in the TT with TC references. The first is "ابن الإيه" and it is used to express admiration for someone who has done something difficult that many cannot do (alJuharī, 2007; Tawfik, 2012). It is substituted in translation with the TC idiom "son of a gun", which is usually uttered to show amazement and surprise (Ammer, 2013). Additionally, it is sometimes employed as "a way of showing affection" for someone (Cambridge International Dictionary of Idioms, 2004, p. 362).

The second SC reference is "حتة واحدة" that describes a person or a thing as remarkably great in some respect ('Amīn, 2013). Here, it refers to a girl as notably beautiful. In translation, it is replaced by "knockout", an informal term that means someone or something is "very attractive or impressive" (Hornby, 2006, p. 819). In this example, substitution succeeds in delivering the meaning of both CRs and in creating an impact on the TA that is similar to the one created on the SA. In other words, both the SC references and their TC equivalents have a familiar effect on their respective audiences. However, this does not come without a loss since substitution is a TC-biased strategy. It mostly results in effacing the specific way or form the SC chooses to represent itself and replaces it with one that belongs to the TC.

Example 14

\begin{tabular}{|c|c|}
\hline ST & TT \\
\hline 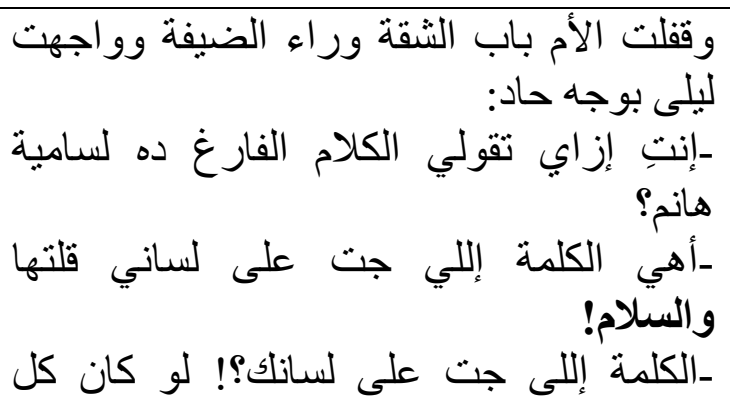 & $\begin{array}{l}\text { Her mother closed the apartment } \\
\text { door behind the guest and turned to } \\
\text { Layla, her face severe. } \\
\text { "How could you say those } \\
\text { ridiculous things to Samia Hanim?" } \\
\text { "I just said what came to my } \\
\text { mind, and that's that!" }\end{array}$ \\
\hline
\end{tabular}


Weaam Sobhy Mohamed Afifi

الدانيا خربت! الكلمة إللي تيجي على لسانه كانت

(al-Zayyat, 2015, p. 43)
"What came to mind? If everyone said whatever was on their mind the world would have gone up in flames long ago."

(Booth, 2002, p. 35)

Here, Layla has spoken informally to and disagreed with Samia Hanim, a relative of her mother's. She is a snobbish lady who is used to everyone agreeing with her because of her high social standard. In the above discussion between Layla and her mother, two SC expressions are used. First, "و is substituted by the TC idiom "that's that" which delivers the intended meaning that something, e.g. a situation or a decision, is already over and nothing about it can be changed (Ammer, 2013; Hornby, 2006). In addition to this connotative meaning, the word "السلام literally means "peace". It is used in its general sense and as a word of farewell. Translating this literally would be unintelligible to the TA in this context, which justifies the application of substitution here.

The second SC idiom, "كانت الدنيا خربت", connotatively means that if a certain act had been committed, great turmoil would have happened leading to extremely serious consequences (al-Juharī, 2007). Translating it into the TC idiom "the world would have gone up in flames" effectively delivers the desired meaning as it denotes the complete destruction of something (Ammer, 2013). Although translating this SC expression literally would also serve this purpose, using substitution here creates a domestic effect on the TA and brings the text closer to them.

Example 15

\begin{tabular}{|c|c|}
\hline ST & TT \\
\hline 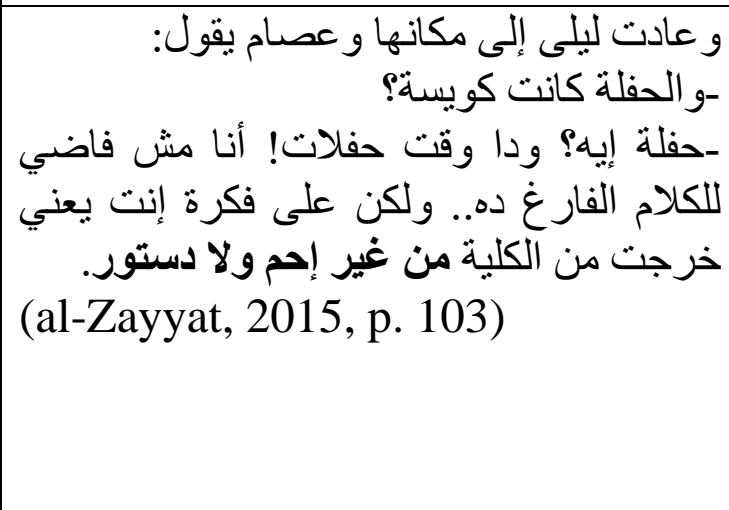 & $\begin{array}{l}\text { Layla sat down again. "Was the } \\
\text { reception good?" Isam asked his } \\
\text { friend. } \\
\text { "What reception? - this is no time } \\
\text { for parties! I don't have time to } \\
\text { think of such nonsense. But by the } \\
\text { way, you left the college without } \\
\text { even a 'so long.'" } \\
\text { (Booth, 2002, pp. 85-86) }\end{array}$ \\
\hline
\end{tabular}

Mahmud and his cousin Isam are students in the Faculty of Medicine, where a tea reception is held. Discussing this matter, Mahmud uses the SC idiom " to wonder why Isam has left the faculty unexpectedly early. This idiom is said to or about someone who has done something suddenly without signalling that he or she is going to do it. Examples include engaging in others' conversations, entering a place or 
The Effect of Cultural Distance on Translating Cultural References in al-Zayyat's The Open Door (1960)

leaving it without warning (al-Juharī, 2007). In translation, Booth also makes use of a TC idiom in place of the SC one, stating that Isam has left without a "so long", which is an informal term for goodbye (Hornby, 2006). As in previous substitution examples, this one conveys the required meaning and prefers familiarity to exoticism. This is especially because a literal translation that keeps the form of this SC reference would block understanding on the part of the TA, in addition to losing the cultural connotations. Weighing the losses, the translator favours the loss of form over the loss of meaning and connotation if another strategy like calque is used here.

The eighth strategy adopted in the TT is compensation. Although it does not appear repeatedly in the translation, it helps deliver the SC features of a CR. This is demonstrated by the subsequent example.

Example 16

\begin{tabular}{|c|c|}
\hline ST & TT \\
\hline 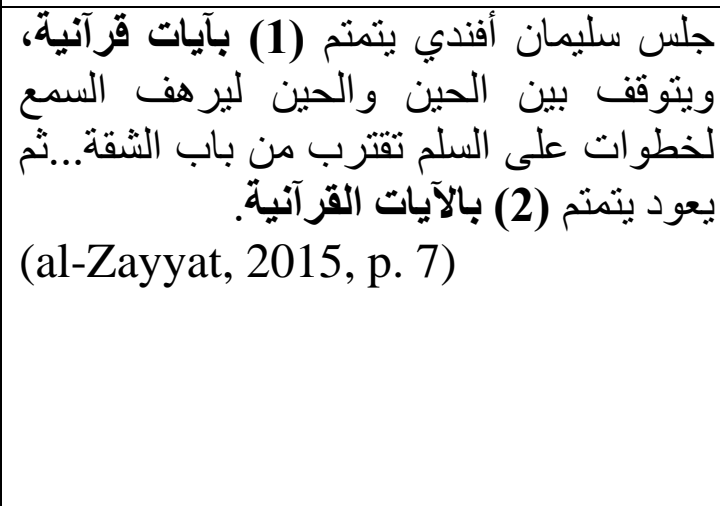 & $\begin{array}{l}\text {... sat Sulayman Effendi himself..., } \\
\text { he was repeating (1) verses from } \\
\text { the Qur'an in an undertone, } \\
\text { stopping from time to time to listen } \\
\text { hard whenever footsteps sounded on } \\
\text { the stairs...Eventually he would } \\
\text { resume his murmured repetition of } \\
\text { (2) verses from the Holy Book. } \\
\text { (Booth, 2002, p. 5) }\end{array}$ \\
\hline
\end{tabular}

This example presents a CR to the Qur'an, that is the Holy Book of Islam. Here, the strategy of compensation is combined with loan and generalization by hypernym, yet it plays a more important role. In (1), the translator renders this SC reference by means of loan, borrowing the term "Qur'an" and using it in the TT without further explanation. Adopting the strategy of loan here attracts attention to this CR and the features of its culture, yet it adds a sense of exoticism to the TT. In (2), the translator decides to use another strategy to translate the very same reference. Here, "الآيات القرآنية" is translated using the strategy of generalisation by hypernym as "verses from the Holy Book". This choice of strategy is not effective in itself, but in the fact that it presents an explanation of the borrowed CR in (1). This is because it is a compensation for the loss of meaning that may result from the verbatim transfer of this CR. Therefore, the strategy of compensation successfully keeps the local colour of the ST without completely impeding understanding on the part of the TA. 


\section{Weaam Sobhy Mohamed Afifi}

Ninth is the strategy of elimination. Although not extremely recurrent, its application in the TT results in neutralizing the SC features or omitting them altogether. This appears in the next example.

\section{Example 17}

\begin{tabular}{|c|c|}
\hline ST & TT \\
\hline 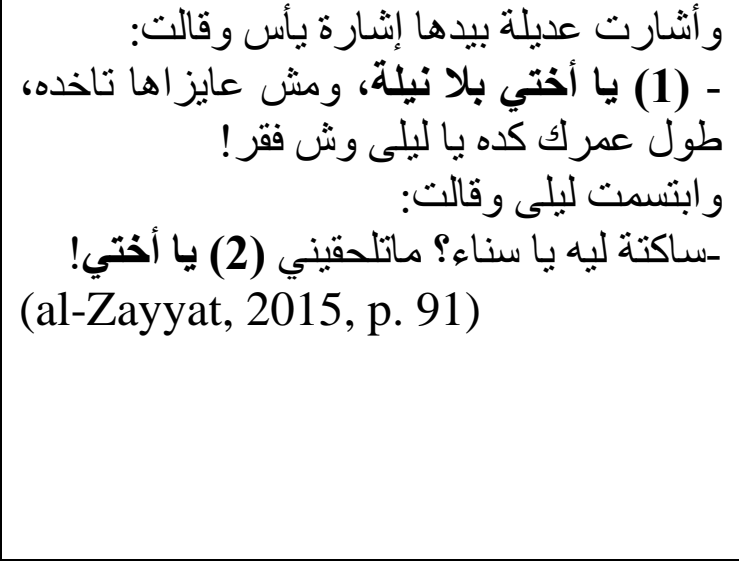 & $\begin{array}{l}\text { Adila flicked her hand toward the } \\
\text { ceiling in offhand despair. "Oh } \\
\text { please, (1) Layla! All that and you } \\
\text { still don't want her to take him? } \\
\text { You've always let the best things } \\
\text { pass you by." } \\
\text { Layla smiled. "Sanaa," she asked, } \\
\text { "why are you so quiet? Help me } \\
\text { out, why don't you!" (Booth, 2002, } \\
\text { p. 76) }\end{array}$ \\
\hline
\end{tabular}

Adila here is counting the impressive financial advantages of Gamila's groom and disagreeing with Layla that she still thinks Gamila should not marry him. In their conversation, two SC references are mentioned. The first is "يا أختي", which is literally translated as "sister". It is an informal term of address usually used among women as a reflection of their close friendly relationship (al-Juharī, 2007). It is frequently used in the SC, especially by middle and lower social classes. This CR occurs twice in the above example and both occurrences are eliminated but in different manners. In (1), "يا أختي is replaced in translation by Layla's name. While this may be suitable in the context of situation, "Layla" is a much more neutral term of address and using it causes the CR and its level of informality to be eliminated. Its status as a recurrent term in the SC is also absent from the TT. In (2), this SC reference does not appear in the TT in any way nor is it replaced by any other term of address.

The second CR mentioned in this example is "بلا نبلة", consisting of

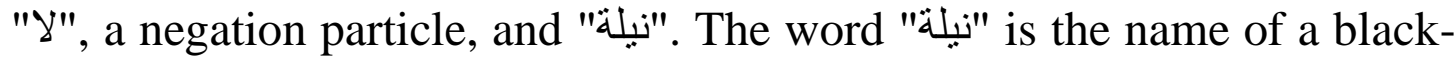
coloured plant and is colloquially used in the SC to describe a thing or a situation as unpleasant and undesirable (al-Juharī, 2007; Tawfik, 2012). Adila uses this expression to comment on Layla's opinion, arguing from her point of view that it is wrong and unreasonable. It is true that the translation of this CR in the TT as "Oh please" shows disapproval (Hornby, 2006). However, the specific meaning of the CR "بلا نيلة itself is not conveyed in translation. Moreover, the ST expression is highly informal, frequently used and deeply rooted in the SC, while "Oh, please" is significantly more neutral and using it causes these cultural connotations to be lost in translation. 
The Effect of Cultural Distance on Translating Cultural References in al-Zayyat's The Open Door (1960)

The tenth and final strategy used in the analysed TT is creative addition. Using this strategy, the translator of The Open Door inserts CRs in the TT that mostly belong to the TC. This is reflected in the subsequent examples.

Example 18

\begin{tabular}{|c|c|}
\hline ST & TT \\
\hline 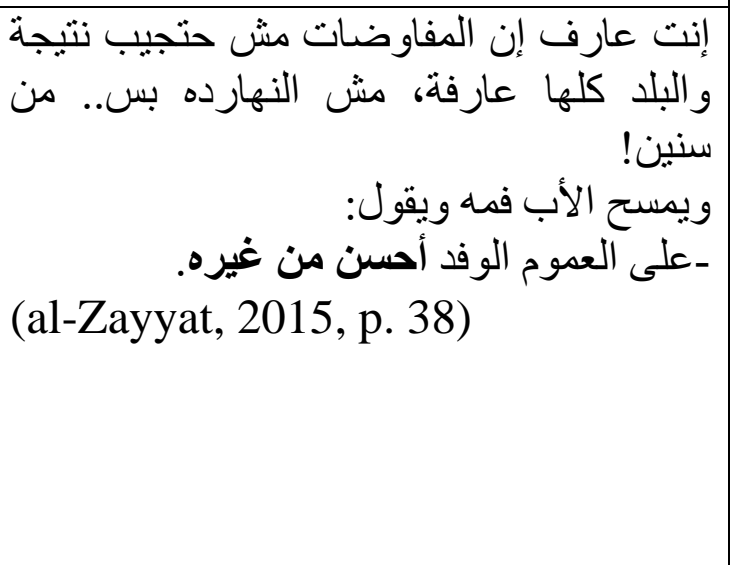 & $\begin{array}{l}\text { You know perfectly well that the } \\
\text { negotiations won't lead to anything. } \\
\text { The whole country knows it, too. } \\
\text { And it isn't as if everyone has just } \\
\text { woken up to the fact - we've all } \\
\text { known it for years." } \\
\text { Wiping his mouth, their father } \\
\text { would join the conversation. "In } \\
\text { any case, the Wafd is the best of } \\
\text { the lot." (Booth, 2002, p. 31) }\end{array}$ \\
\hline
\end{tabular}

Here, during lunch, Mahmud is having a discussion with his father and Isam about the political affairs of the country. At that time, the most popular political party, the Wafd, formed the government and was engaged in long and futile negotiations with the English side for achieving the full independence of Egypt. Mahmud is angry as he believes the Wafd has betrayed the people's trust by agreeing to continue such negotiations. The father still believes that the Wafd party is أحسن من " "غيره, which literally means "better than others". In translating the father's opinion, Booth decides to make a creative addition by introducing a CR in the TT although the father's words include none. She uses the TC idiom "the best of the lot" to describe the Wafd, which is defined as "the most excellent of all people or things considered as a group" (Heacock, 2003 , p. 28). Such creative additions that present TC references make the TT closer, more natural and more familiar to the TA. It may also play a role in giving them a feeling of sharing common ground with the SC that makes it possible for it to be expressed in their words.

Example 19

\begin{tabular}{|c|c|}
\hline $\begin{array}{c}\text { ST } \\
\end{array}$ & TT \\
\hline 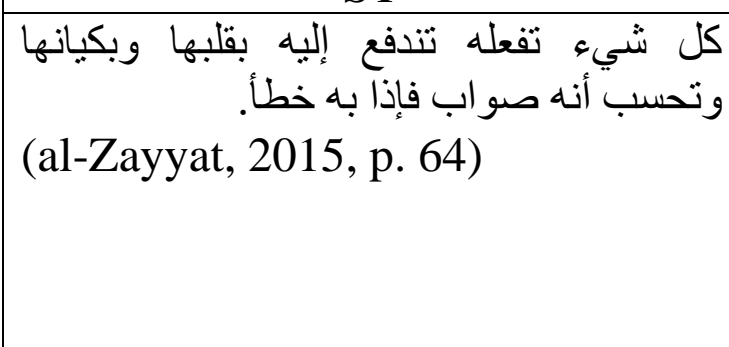 & $\begin{array}{l}\text { Everything she did, she did with her } \\
\text { whole heart, she pitched right in, } \\
\text { heart and soul, and she always } \\
\text { thought that was right, but lo and } \\
\text { behold, every time it turned out to } \\
\text { be wrong. (Booth, 2002, p. 54) }\end{array}$ \\
\hline
\end{tabular}


In this instance, two TC idioms are creatively added in the TT, i.e. "heart and soul" and "lo and behold". The first idiom indicates doing something with great excitement, passion and eagerness (Hornby, 2006), which is a trait of Layla's character, at least at this stage of the novel. The second expression, "lo and behold", is generally said humorously by people who want to shed light on something that irritates or amazes them (Hornby, 2006). This idiom is used here rather sarcastically, which highlights Layla's emotions. In addition to giving the TT a more domestic atmosphere, introducing these idioms emphasizes Layla's character and the elements of her story. Here, Layla is having one of her many interior monologues that expresses her internal conflict. This conflict is a result of another external one with her society, many of whose customs she is unable to accept. Consequently, she gets the feeling that she is rejected and does not fit in with the people around her. The translator's creative additions here serve and reflect those aspects.

Based on the examples analysed above, some conclusions can be drawn. The present study has examined a number of selected CR examples from an Arabic novel, namely The Open Door, and its English translation, adopting Ranzato (2013) as a model of analysis. This has been done with the aim of investigating how the relatively wide distance between the SC and the TC impacts the translation of CRs. Generally, CRs represent a problematic area in translation, and the problems they create become even more challenging when they are being translated between two distinct and distant cultures.

The analysis of the examples shows that the distance between the SC and the TC becomes most evident with SC references, which are frequent in the ST. This gap is mainly attributed to the fact that each of the two cultures develops unique concepts and formulates different elements, phrases, tools, etc. to express itself. Such tools and elements result from several factors related to history, geography, social developments and religion, among others. Not all these differences can be balanced in translation. Based on this and through the analysis, the study reveals that the distance between the $\mathrm{SC}$ and the TC has had a significant influence on the translation of CRs in The Open Door. This influence appears in several aspects. First, in some cases, the functional and/or universal meanings of a $\mathrm{CR}$ are conveyed in translation, while its peculiar cultural usage, connotations and status in the SC are not transferred. Second, in other cases, the translator has been able to deliver the meaning of the CR in its context of situation, but not its meaning(s) in the context of culture. Third, the effect exerted by the CR on the SA is mostly different from that exerted by its translation on the TA. In other words, what is familiar/foreign for the SA in the ST is not usually made so in the 
The Effect of Cultural Distance on Translating Cultural References in al-Zayyat's The Open Door (1960)

TT. Fourth, multiple-meaning CRs that belong to the SC are either generalized or partly delivered.

Fifth, the distance between the SC and the TC can sometimes drive the translator's choice of strategy, making some strategies more preferred than others in certain cases. For instance, a strategy like calque is avoided at times, because keeping the specific form used by the SC will produce an incomprehensible translation. Other strategies such as substitution may be favoured in these cases and in others where the translator desires to mitigate the foreignness of the text. This desire also urges the translator to apply the strategy of creative addition. Another choice of strategy motivated by the distance between the SC and the TC is explicitation, as it assists the translator in striking a balance between keeping as much as possible of the SC and making it understandable to the TA.

Accordingly, it can be drawn that there are three levels of minimizing the gap between the SC and the TC in the specific case of translating CRs. From lower to higher, those levels are: a) conveying meaning, b) conveying meaning and form, and c) conveying meaning, form and cultural associations. The study observes that the strategy of explicitation is the one that helps most in minimizing this gap. This is because it allows the translator to maintain the SC references and distinctive features, and to provide extra information that aids the TA to recognize as much as possible of the various aspects of these references.

It is hoped that the present study is useful to other researchers interested in the translation of CRs between Arabic and English since it draws attention to the problems they create and the effects of the strategies used for translating them. At times, the gap between the SC and the TC leads to some kind of loss, either in respect to the meaning, form, or cultural connotations of a CR. This may be the inevitable loss in translation that is to be expected. However, efforts should be made to examine these losses through more research to help deal with them.

The present study has focused on one Arabic novel and its English translation. Other studies can analyse a larger corpus of similar texts. Such studies can be conducted on the several translations of the same novel, comparing how translators who belong to the SC and those who belong to the TC deal with CRs. 


\section{Weaam Sobhy Mohamed Afifi}

\section{Notes}

${ }^{1}$ Cintas and Remael's taxonomy was first proposed in 2007 in their Audiovisual Translation: Subtitling published by St. Jerome. In discussing their classification of CRs and their translation strategies, the researcher is referring to the reprint of the book published by Routledge in 2014. 
The Effect of Cultural Distance on Translating Cultural References in al-Zayyat's The Open Door (1960)

\section{References}

Aixelá, J. F. (1996). Culture-specific items in translation. In R. Álvrez \& M. C.-A. Vidal (Eds.), Translation, power, subversion (pp. 52-78). Clevedon, England: Multilingual Matters. Retrieved from https://books.google.com.eg/books?id=R1p5Q613iuQC\&printsec=frontc over\&dq=Translation,+ Power,+ Subversion $\&$ hl $=$ en $\& s a=X \& v e d=0$ ahUK EwjIpvuV1LjKAhUEwBQKHQyhAGkQ6AEIGjAA\#v=onepage\&q=Tr anslation\%2C\%20Power\%2C\%20Subversion \&f=false on Tue. 19/1/2016 at 10:14 PM

al-Bannā, N. (2016, September 4). Fī mithl hadha al-yawm: Muḩārabat aţţabaqiyah wa 'ilghā' al-'alqāb al-madaniyah [On this day: Fighting caste and abrogating civil titles]. 'Akhbār al-Yawm. Retrieved from https://akhbarelyom.com/news/newdetails/554800/1/\%D9\%81\%D9\%8A -\%D9\%85\%D8\%AB\%D9\%84-\%D9\%87\%D8\%B0\%D8\%A7-

\%D8\% A7\%D9\%84\%D9\%8A\%D9\%88\%D9\%85\%D9\%85\%D8\%AD\%D8\%A7\%D8\%B1\%D8\%A8\%D8\%A9\%D8\%A7\%D9\%84\%D8\%B7\%D8\%A8\%D9\%82\%D9\%8A\%D8\%A9\%D9\%88\%D8\%A5\%D9\%84\%D8\%BA\%D8\%A7\%D8\%A1\%D8\%A7\%D9\%84\%D8\%A3\%D9\%84\%D9\%82\%D8\%A7\%D8\%A8\%D8\%A7\%D9\%84\%D9\%85\%D8\%AF\%D9\%86\%D9\%8A\%D8\%A9 on Mon. 24/6/2019 at 11:15 AM

al-Juharī, M. (2007). Mu 'jam lughat al-hayāh al-yawmiyah [A dictionary of everyday language]. Cairo, Egypt: al-Maktabah al-'Akādīmiyah.

al-Zayyat, L. (2002). The open door (M. Booth, Trans.). Cairo, Egypt: The American University in Cairo Press. (Original work published 2000)

al-Zayyat, L. (2015). al-Bāb al-maftūh [The open door]. Cairo, Egypt: alKarma Publishers. (Original work published 1960)

'Amīn, A. (2013). Qūmūs al- 'ādāt wat-taqālīd wat-ta'ābìr al-mişriyah [A dictionary of Egyptian customs, traditions and expressions]. Cairo, Egypt: Hindawi.

Ammer, C. (2013). The American Heritage dictionary of idioms: American English idiomatic expressions and phrases ( $2^{\text {nd }}$ ed.). Boston, MA: Houghton Mifflin Harcourt. Retrieved from https://books.google.com.eg/books?id=9QuEiIMaBt0C\&printsec=frontc over\&dq=the+american+heritage+dictionary+of+idioms\&hl=en\&sa $=X$ \&ved=0ahUKEwjJ6brqhJHiAhVNQhoKHWl-

AOAQ6AEIKzAB\#v=onepage\&q=the $\% 20$ american $\% 20$ heritage $\% 20$ dic tionary\%20of\%20idioms\&f=false on Fri. 10/5/2019 at 3:28 PM

Baalbaki, R. (2007). al-Mawrid: A modern Arabic-English dictionary (21 ${ }^{\text {st }}$ ed.). Beirut, Lebanon: Dar El-Ilm Lilmalayin.

Cambridge international dictionary of idioms. (2004). Cambridge, England: Cambridge University Press. 
Cintas, J. D., \& Remael, A. (2014). Audiovisual translation: Subtitling. Abingdon, England: Routledge.

Dickins, J., Hervey, S., \& Higgins, I. (2002). Thinking Arabic translation: A course in translation method: Arabic to English. Abingdon, England: Routledge.

Dubrin, B. (2012). Tea culture: History, traditions, celebrations, recipes \& more. Watertown, MA: Charlesbridge. Retrieved from https://books.google.com.eg/books?id=WMcNCwcCPpgC\&pg=PA18\& dq=tea+culture+in+Britain\&hl=en\&sa=X\&ved=0ahUKEwiQ69_cqZzU AhVIWxQKHVPvCC8Q6AEIOjAF\#v=onepage \&q=tea\%20 culture $\% 20$ in\%20Britain\&f=false on Thu. 1/6/2017 at 11:53 AM

Ferdman, R. A. (2014, September 3). America is slowly - but surely becoming a nation of tea drinkers. The Washington Post. Retrieved from https://www.washingtonpost.com/news/wonk/wp/2014/09/03/americais-slowly-but-surely-becoming-a-nation-of-tea-drinkers/on Thu. 1/6/2017 at 12:24 PM

Guerra, A. B. F. (2012). Crossing boundaries: The translation of cultural referents in English and Spanish. Word and Text: A Journal of Literary Studies and Linguistics, 2(2), 121-138.

Heacock, P. (Ed.). (2003). Cambridge dictionary of American idioms. Cambridge, England: Cambridge University Press. Retrieved from https://books.google.com.eg/books?id=ytJNRDL0zDgC\&dq=\%22the+b est+of+the+lot\%22+idiom\&source=gbs_navlinks_s on Fri. 12/7/2019 at 6:16 PM

Hornby, A. S. (2006). Oxford advanced learner's dictionary of current English ( $7^{\text {th }}$ ed.). Oxford, England: Oxford University Press.

Irwin, R. (2004). Futuwwa: Chivalry and gangsterism in medieval Cairo. Muqarnas, 21, 161-170.

Jacob, W. C. (2007). Eventful transformations: al-Futuwwa between history and the everyday. Comparative Studies in Society and History, 49(3), 689-712.

Katan, D. (2009). Translation as intercultural communication. In J. Munday (Ed.), Routledge companion to translation studies (pp. 74-92). Abingdon, England: Routledge.

Katan, D. (2014). Intercultural communication, mindful translation and squeezing "culture" onto the screen. In B. Garzelli \& M. Baldo (Eds.), Subtitling and intercultural communication: European languages and beyond (pp. 55-76). Pisa, Italy: Edizioni ETS.

Merriam-Webster online dictionary. (2019). Retrieved from https://www.merriam-webster.com/

Newmark, P. (1988). A textbook of translation. Upper Saddle River, NJ: Prentice Hall.

Pedersen, J. (2005). How is culture rendered in subtitles? In H. GerzymischArbogast \& S. Nauert (Eds.), MuTra-Challenges of Multidimensional 
The Effect of Cultural Distance on Translating Cultural References in al-Zayyat's The Open Door (1960)

Translation: Conference Proceedings (pp. 1-18). Stockholm, Sweden: Advanced Translation Research Center.

Ranzato, I. (2013). The translation of cultural references in the Italian dubbing of television series (Doctoral dissertation, Imperial College London, England).

Tawfik, K. (2012). 'Uşūl al-'alfāz, wat-ta 'bìrāt al- 'āmmiyah [The etymology of colloquial words and expressions]. Giza, Egypt: Hala.

Taymūr, A. (2014). al-'Amthāl al-'āmmiyah [Colloquial proverbs] . Cairo, Egypt: Hindawi.

'Umar, A. M. (2008). Mu'jam al-lughah al-'arabiyah al-mu'āşirah [A dictionary of contemporary Arabic ]. Cairo, Egypt: 'ālam al-kutub.

Vinay, J.-P., \& Darbelnet, J. (1995). Comparative stylistics of French and English: A methodology for translation (J. C. Sager \& M.-J. Hamel, Trans.). Amsterdam, the Netherlands: John Benjamins. (Original work published 1958) 